\title{
Fears, anxieties and cognitive- behavioral treatment of specific phobias in youth
}

\author{
Lena Reuterskiöld
}

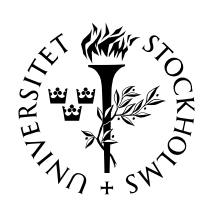

Stockholm University 
(C) Lena Reuterskiöld, Stockholm 2009

Cover illustration is reprinted with permission

from Cathrine and Peter Eijvergård

ISBN (978-91-7155-794-0)

Printed in Sweden by US-AB, Stockholm 2009

Distributor: The Department of Psychology, Stockholm University

ii 
To Staffan, Mathias and Madeleine 


\section{Abstract}

The present dissertation consists of three empirical studies on children and adolescents presenting with various specific phobias in Stockholm, Sweden and in Virginia, USA. The overall aim was to contribute to our understanding of childhood fears, anxiety and phobias and to evaluate the efficacy and portability of a one-session treatment of specific phobias in youth. Study I tested the dimensionality of the Parental Bonding Instrument, across three generations and for two countries, and examined if parenting behaviors of indifference and overprotection were associated with more anxiety problems in children. The results showed that the four-factor representation of parental behavior provided an adequate fit for the instrument across informants. Perceived overprotection was associated with significantly more anxiety symptoms and comorbid diagnosis in children. Study II explored parent-child agreement on a diagnostic screening instrument for youths. The results indicated that children scoring high on motivation at treatment entry had generally stronger parent-child agreement on co-occurring diagnoses and severity ratings. Parents reported overall more diagnoses for their children, and parents who themselves qualified for a diagnosis seemed more tuned in to their children's problematic behavior. Study III compared a one-session treatment with an education-supportive treatment condition, and a wait-list control condition for children presenting with various types of specific phobias. The results showed that both treatment conditions were superior to the wait-list control condition and that one-session exposure treatment was superior to education-supportive treatment on several measures. Treatment effects were maintained at a 6month follow-up. Overall, the above findings suggest that the one-session treatment is portable and effective in treating a variety of specific phobias in children and adolescents.

Keywords: Specific phobia, one-session treatment, child anxiety, parenting, motivation, assessment, parent diagnoses, cognitive-behavioral therapy 


\section{Acknowledgements}

It all started with a question. I approached Professor Lars-Göran Öst in late fall 2002, and asked if there was a part-time position available where there was a possibility of combining CBT with clients and research. I remember him listening intently, seriously, and then breaking into a smile with a speedy solution. "Well, then you will have to become my $\mathrm{PhD}$ student!". Thus, in January 2003, I became involved in three research projects for children and adolescents with specific and social phobias, and new colleagues who were both inspiring and fun to be with. So a first thank you to my supervisor for support, patience and guidance during this challenging journey.

There are many colleagues who deserve mention in a large research project such as the present one. First, a special thank you to Professor Thomas Ollendick for sharing your knowledge and giving sound advice, and to my closest doctoral colleague and friend during these years of data collection and late night studies Rio Cederlund "you're the best!". I am also gratefully indebted to Ann-Charlotte Smedler of the Department of Psychology, Stockholm, and to Anders Broberg, of the Department of Psychology, Göteborg, for their review and valuable comments on this thesis, and to Professor Magnus Sverke for his collaboration and creative work on study I.

I would like to extend great thanks to the following present and past colleagues at the clinical department, in no particular order, who made this thesis possible. The therapists in the project Ulrika Thulin, Liv Svirsky, Elin Wesslander and Åsa Larsson. The research assistants who helped keep the project together, Bella Stensnäs and Mari Ljungström, and to Jonas Ramnerö, Sara Widén, Elisabeth Breitholtz, Ulrika Långh, Johan Holmberg and Gunilla Berglund for theoretical discussions and inspiring lunches.

To colleagues and friends in House 8 for general support and encouragement along the way Ulla Ek, Bo Heffler, Hi-Young Kim, Billy Jansson, AnnaKarin Berger, Jane Olsson, Kerstin Halldin, Margareta Simonsson-Sarnecki, and in House 14: Anna-Lena Erixon, Jenny Laurell, Heidi Selenius, Gustav Thörngren, Johan Willander, and to Christina Flordh and Bo Schenkman. 
My dear neighbors and friends, Cathrine, Peter and Ann, thank you for your generosity and joyful company through many years, in Antiparos and back at home.

To my family: First a thank you to my parents, Lill and Göran, who gave me a good start in life, and to Olle for many joyful moments. To my relatives in Göteborg, my grandmother Gudrun and Aunt Ulla. The West coast is fantastic!

A big thank you to my children, Mathias and Madeleine, who have accompanied me during all these years, you're both adults now and I am so proud of you! To my husband, Staffan who has been up late waiting for me and given praise and encouragement when the workload was tough! And to our Bergamasco Sixten, for nice walks in the woods and for just being so cool....

A big heart to the our dog owners and dogs who participated in the treatments, and in all the behavioral tests. Also I'm indebted to the personnel at Aquaria, Stockholm, for the loan of their "rain forest".

Finally, great thanks are extended to the parents and children, from Sweden and Virginia, who participated in this large research project! Thank you! 


\section{List of studies}

The present doctoral thesis is based on the following studies, which will be referred to by their Roman numerals:

I. Reuterskiöld, L., Sverke, M., Ollendick, T., \& Öst, L.-G. (manuscript). Parenting and childhood anxiety: A clinical study in Sweden and Virginia.

II. Reuterskiöld, L., Öst, L-G., \& Ollendick, T. (2008). Exploring child and parent factors in the diagnostic agreement on the Anxiety Disorders Interview Schedule. Journal of Psychopathology and Behavioral Assessment, 30, 279-290.*

III. Ollendick, T., Öst, L-G., Reuterskiöld, L., Costa, N., Cederlund, R., Sirbu, C., Davis III, T. E., \& Jarrett, M. (in press). Onesession treatment of specific phobias in youth: A randomized clinical trial in the USA and Sweden. Journal of Consulting and Clinical Psychology.

* Reprinted with permission from the publisher 


\section{Contents}

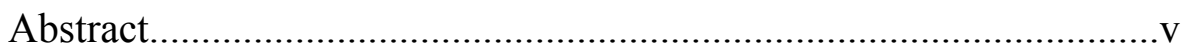

Acknowledgement.................................................................vii

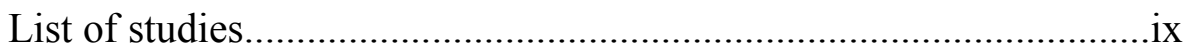

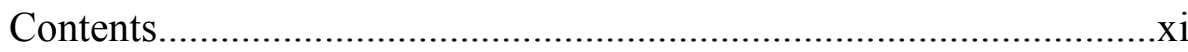

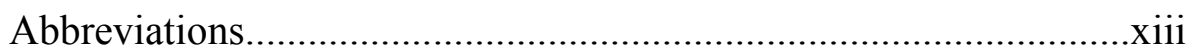

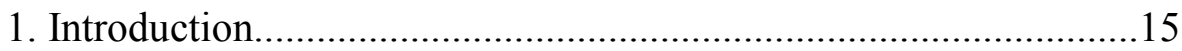

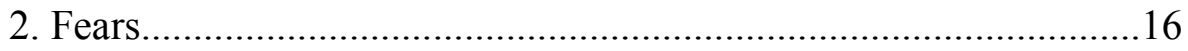

2.1. Normal development of fears.............................................................16

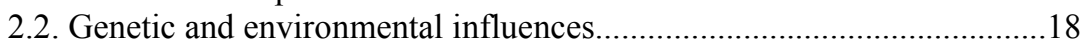

3. Etiology of phobic and anxiety disorders.....................................20

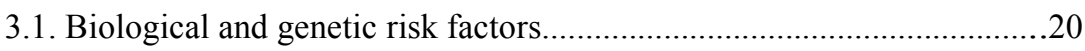

3.2. Psychological models........................................................................20

4. Specific phobias.................................................................23

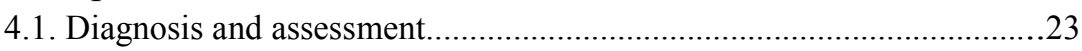

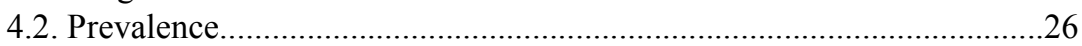

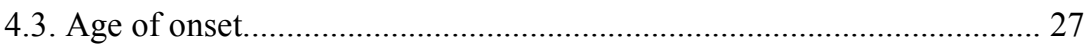

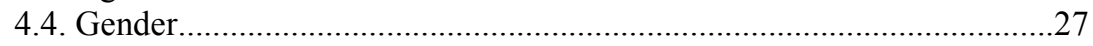

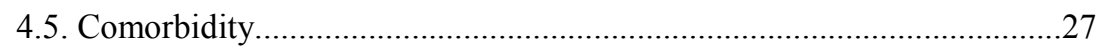

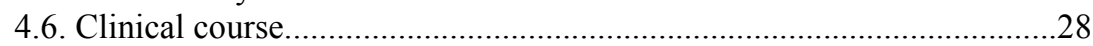

5. Parenting behaviors and childhood anxiety..................................30

5.1. A genetic-epidemiologic perspective of parenting..................................30

5.2. Perceived poor parenting and anxiety in children....................................32

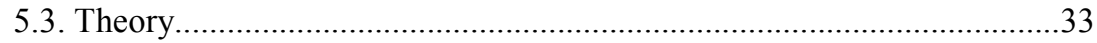

6. Parent-child agreement on child diagnosis.....................................34

6.1. Agreement on anxiety disorders.................................................. 34

6.1.1. Child factors.................................................................. 34 
7. Randomized treatment studies of specific phobias in children........37

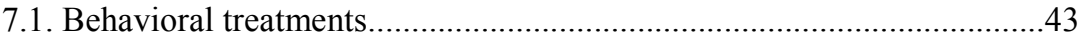

7.1.1. Systematic desensitization and its variants..................................43

7.1.2. Emotive imagery.......................................................................4 47

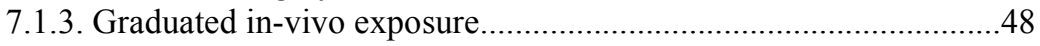

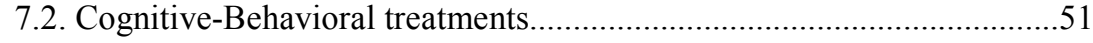

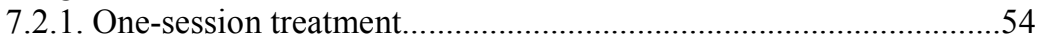

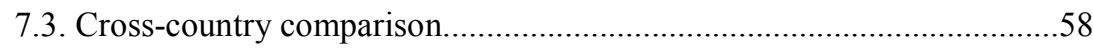

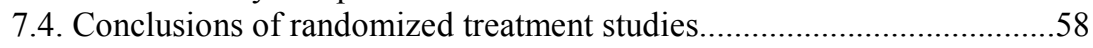

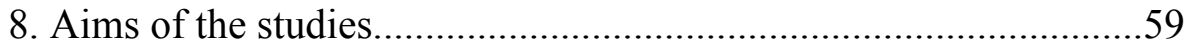

9. Overview of empirical studies............................................6 60

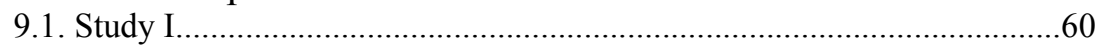

9.1.1. Aims.....................................................................................6

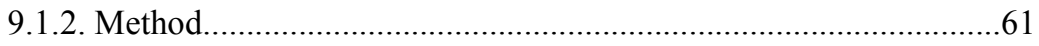

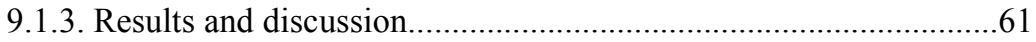

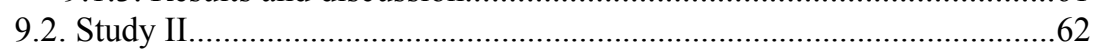

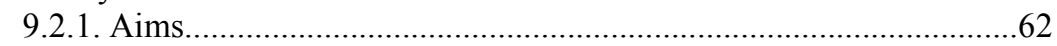

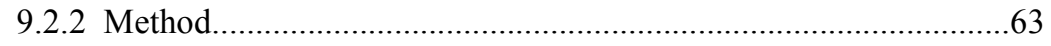

9.2.3. Results and discussion..........................................................64

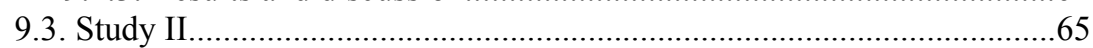

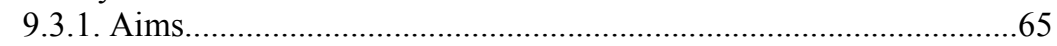

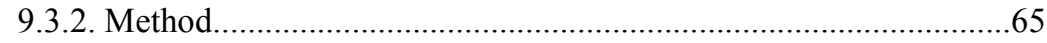

9.3.3. Results and discussion..........................................................66

10. General discussion.........................................................68

10.1. Parenting and childhood anxiety in a clinical sample in

Sweden and Virginia......................................................................6

10.2. Parent-child agreement on anxiety disorders.....................................69

10.3. Cognitive Behavioral treatment of specific phobia in

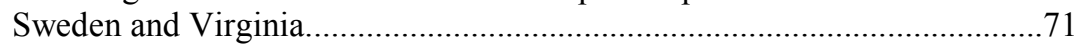

10.4. Methodological comments and limitations........................................ 73

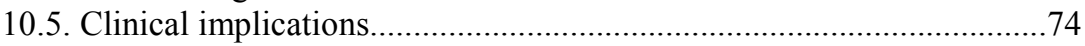

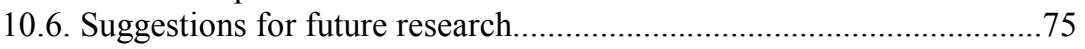

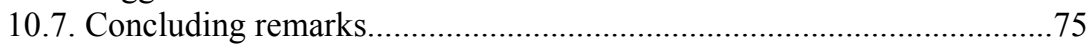

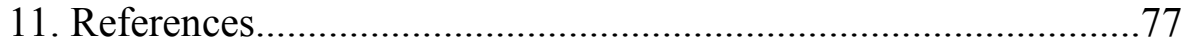




\section{Abbreviations}

$\begin{array}{ll}\text { ADIS-C/P } & \begin{array}{l}\text { Anxiety Disorders Interview Schedule, Child and } \\ \text { Parent versions }\end{array} \\ \text { BAT } & \text { Behavioral Approach Test } \\ \text { CBCL } & \text { Child Behavior Checklist } \\ \text { CBT } & \text { Cognitive-Behavioral Treatment } \\ \text { CMT } & \text { Contingency Management Treatment } \\ \text { CSI } & \text { Clinically Significant Improvement } \\ \text { DSM-IV/III-R } & \text { Diagnostic and Statistical Manual of Mental } \\ & \text { Disorders, } 4^{\text {th }} / 3^{\text {rd }} \text { edition, Revised } \\ \text { EMDR } & \text { Eye Movement Desensitization and Reprocessing } \\ \text { EST } & \text { Education-Supportive Therapy } \\ \text { FSSC-R } & \text { Fear Survey Schedule for Children-Revised } \\ \text { GAD } & \text { Generalized Anxiety Disorder } \\ \text { MASC } & \text { Multidimensional Anxiety Scale for Children } \\ \text { OST } & \text { One Session Treatment } \\ \text { RCT } & \text { Randomized Controlled Treatments } \\ \text { PBI } & \text { Parental Bonding Instrument } \\ \text { SAD } & \text { Separation Anxiety Disorder } \\ \text { SOP } & \text { Social Phobia } \\ \text { SP } & \text { Specific Phobia } \\ \text { SUD } & \text { Subjective Units of Distress } \\ \text { WLC } & \text { Wait-list Control Group }\end{array}$




\section{Introduction}

Fears, anxieties and specific phobias, often classified as internalizing behavior problems, are all relatively common among children and adolescents of today (Lichtenstein \& Annas, 2000). Looking back, studies of fears in youth and young adults were already being conducted in 1897 by Hall. In this study, the top ten common fears, in 1701 persons aged 0 to 26 years, were reported to be thunder storms, reptiles, strangers, darkness, fire, death, domestic animals, disease, wild animals and water, with an average of 3.6 fears per person (Hall, 1897). Despite this early start, it is not until the last decades that researchers have, in a more systematic way, started to focus on this population, gathering data to answer questions about the epidemiology, etiology and the development of fears, anxiety and phobias. To this end much effort has also been applied to developing models of fear acquisition and more broadly on anxiety disorders, their maintenance and treatment. This work is important in two ways: First, Graziano, DeGiovanni and Garcia (1979) concluded in their review that there was a striking lack of progress in the study of children's fears; second, the area seems especially important as two meta-analytic studies found self-reports of anxiety (across four different measures of anxiety) to have increased by one standard deviation, during a period of forty years (1952-1993) (Twenge, 2000). These results were replicated in a second study, in samples of school children (aged 9 to 17 years). In order to understand the magnitude of the birth cohort change in anxiety, the author reported that in the 1980s normal child samples were scoring higher than child psychiatric patients in the 1950s (Twenge, 2000). It should be mentioned, though, that the samples in these studies were collected from the USA and thus it is difficult to know how these results might generalize to samples in other countries.

The overall aim of the present thesis is to contribute to our understanding of fears, anxiety and specific phobias in children and adolescents as they present in two clinical research settings, in Sweden and Virginia. More specifically, to examine parental rearing behaviors and their relation to child anxiety and comorbid disorders in this sample of children, parent-child agreement on reported child anxiety disorders, and to evaluate the efficacy and portability of a one-session treatment of various specific phobias in youth across Sweden and Virginia. 


\section{Fears}

Fear is a basic human emotion usually defined as a normal response to objects or situations that pose a threat to personal and physical safety, characterized by an outer behavioral expression, an inner subjective distress and associated physiological changes (Marks, 1969).

\subsection{Normal development of fears}

In the literature on anxiety and childhood anxiety disorders, fears are generally considered to be an immediate defensive reaction to threatening stimuli, whereas anxiety is defined as being a more diffused response with apprehension about some future event (Beidel \& Turner, 2005; Johnson \& Melamed, 1979). A phobia, on the other hand, is defined as being an excessive fear that is characterized as being out of proportion to the demands of the situation; cannot be explained or reasoned away; is beyond voluntary control and leads to avoidance of the feared situation (Marks, 1969).

In the course of development, children are reported to have a predictable array of normal intense specific fears that emerge, level off and decline (Beidel \& Turner, 2005; Marks, 1987; Ollendick, Yang, King, Dong, \& Akande, 1996). Some fears start in infancy (e.g., intense unexpected noises, heights), and other types of fears are reported to occur in age periods, 1-2 years (e.g., strangers), 3-5 years (e.g., animals, dark, imagery creatures), 6-9 years (e.g., animals, storms, school, death), 9-12 years (e.g., tests, personal health) and 13 years and older (e.g., personal injury, social interactions and political catastrophes) (Beidel \& Turner, 2005). Young children are also reported to have both more and intense fears than adults, for the fears to be transitory, with a majority ( $72 \%$ ) decreasing over a six month period (Marks, 1987).

Ollendick and King (1994) explored the prevalence of self-reported fears using the Fear Survey Schedule for Children-Revised (FSSC-R) in 12 year old Australian youths. In this study fears were found to be highly prevalent, with an average of nine fears reported, and of the ten most common fears, eight concerned physical danger and safety. In a later study by Svensson and Öst (1999), using the same self-report measure, in Swedish school children aged between 8 and 16 years, fears were found to be similar, although the 
rank order varied. Similarly, in a cross-cultural comparison of self-reported fears in 1200 youths, between 7 and 17 years of age, the ten most common fears across four countries (America, Australia, China and Nigeria) were based on the physical danger and safety factors (e.g., not being able to breathe, being hit by a car or truck, bombing attacks) and on the failure and criticism factors (e.g., failing a test, my parents arguing), however, the number of children endorsing each of these fears differed by country (Ollendick et al., 1996). Although many child fears parallel those found in Western samples (United States, England and Australia) (Dong, Yang, \& Ollendick, 1994), the differences that have emerged in both number and types of fear between Western and Asian and African countries (e.g., higher social-evaluative fears, and guilt), have been interpreted within a cultural developmental context. In this cross-cultural hypothesis it has been suggested that cultures reinforcing compliance, obedience and inhibition give rise to more over controlled problems (Dong et al., 1994; Ollendick et al., 1996; Weisz, Sigman, Weiss, \& Mosk, 1993), in comparison with the greater independence allowed, for example, in the USA (Weisz et al., 1993). Interestingly though, cross-cultural experimental studies have reported greater cooperative behaviors among African than American children, also suggested to be due to strong pressures for compliance (Munroe \& Munroe, 1977).

Most studies on fears in children and adolescents have found that girls report more fears overall (Elbedour, Shulman, \& Kedem, 1997; Hall, 1897; Ollendick \& King, 1994; Ollendick et al., 1996), and also higher levels of fears than boys, in America, Australia and China (Ollendick et al., 1996). In contrast, in the cross-cultural study by Ollendick et al. (1996), Nigeria was the only country where reported fearfulness in boys and girls did not differ. It was noteworthy, though, these children reported significantly more fears than did children in the other three countries. In Sweden the reported results have been more contradictory, with two studies finding more fearfulness in girls (Kendler et al., 2008; Lichtenstein \& Annas, 2000), but, in contrast, Svensson and Öst (2001) reported fearfulness not to differ between boys and girls, in Sweden. Explanations for the discrepancy could be the use of parental report of children's fears in some studies and the use of children's own report in others, the use of different instruments to measure fear, and the representativeness of the samples.

As previously noted, younger children (Elbedour et al., 1997; Svensson \& Öst, 1999), and younger adolescents (Ollendick \& King, 1994), report more and significantly higher levels of fear than older adolescents. Also a general decline in fears was noted in American, Australian and overall in Chinese youths, but no age differences were found in Nigerian youths (Ollendick, et al., 1996). It is difficult, though, from cross-sectional studies to ascertain whether this is a "true" decline, or whether adolescents are more averse to reporting on their fears, perhaps due to social desirability, and not wanting to 
be seen to be different. In the interim, the work done on fears in youths seems important, as one study revealed that $60 \%$ of fearful youths reported that their fears caused them such considerable distress that it interfered with their daily activities and hindered them from doing things they wanted or felt they ought to do (Ollendick \& King, 1994). Thus, even if many fears that emerge are reported to level off and decline, it is apparent that many children and adolescents suffer in the meantime.

\subsection{Genetic and environmental influences}

A number of factors are believed to play a role in the acquisition of severe fears, phobic and anxiety disorders (Beidel \& Turner, 2005; Lichtenstein \& Annas, 2000; Silverman \& Moreno, 2005). Twin and adoptions studies are useful methods to disentangle the contribution that genetics and the environment might have on fears, phobias and other anxiety problems. Such studies, especially in young children are scarce, however, one relevant twin study was found on 8 to 9 year olds (Lichtenstein \& Annas, 2000). Briefly, the authors acknowledged the complexity of the influences and reported that overall genetic effects seem to contribute to both a general susceptibility for fearfulness and a specific fearfulness. Whereas shared environmental effects primarily contribute to common anxiety dimensions (i.e., a general susceptibility to fearfulness) nonshared environmental effects were reported to be fear specific. Moreover, heritable factors as well as environmental factors, such as trauma, vicarious learning and/or negative information, are reported to be important for differences in fearfulness and phobias, at least in young children (Lichtenstein \& Annas, 2000).

Another twin study assessed the intensity of self-reported fears in older twins, from early adolescence to young adulthood. Overall, genetic effects were found across the seven fear factors studied (negative social interaction; social responsibility; dangerous places; small organisms; deep water; loved one's misfortunes and personal death), but the magnitude of the effects were reported to vary with different fears (Rose \& Ditto, 1983).

In a recent longitudinal study by Kendler et al. (2008) on 2490 Swedish twins aged 8-20 years, risk factors for animal, situational and blood-injury fears were examined. Here, two hypotheses were pitched against each other: "developmentally stable" (a single set of genes impacts the level of fears throughout development) and "developmentally dynamic" (genetic effects on fear-proness varies across time). The main findings lend support to the developmentally dynamic hypothesis. Interestingly, genetic factors influencing fear intensity at age 8 to 9 years were reported to decline in importance over time and further, that new sets of genetic risk factors impacting fear intensity emerge both in early adolescence, late adolescence 
and early adulthood. Overall, as twins grow older, the effects of shared environment were reported to decline and the effects of unique environment to increase (Kendler et al., 2008). This might not be so surprising because, in time, with moving away from home and finding other important relationships and contexts in which to interact, the influence of the childhood shared environment is likely to lessen. Unfortunately, in this study, partial attrition over the four assessment points reduced its power.

In conclusion one might ask how this genetic influence actually works to affect fears and phobias. Although a detailed description is beyond the scope of this dissertation, Lichtenstein and Annas (2000) suggest that genetic effects are mediated through biological pathways, like the serotonin (5hydroxy-tryptamine) transporter gene. Kagan and Snidman (1991) suggest that two early and moderately stable temperamental characteristics of children, termed inhibition and uninhibition, with associated differential sympathetic reactivity (e.g., larger heart rate acceleration, pupillary dilatation), under partial genetic control, predict later avoidance or approach behaviors in children. 


\section{Etiology of phobic and anxiety disorders}

\subsection{Biological and genetic risk factors}

From twin studies on children and adults there is evidence suggesting a genetic component in the acquisition of fear, phobic and anxiety disorders (Lichtenstein \& Annas, 2000; Rose \& Ditto, 1983; Silverman \& Moreno, 2005), and these disorders are often reported to "run in families". However, as mentioned earlier, it is difficult to disentangle accurately what is due to genetic and environmental effects respectively, a task made more difficult as longitudinal twin studies in very young children are sorely lacking.

Other risk factors that are suggested to be important contributors to anxiety disorders and specific phobia in youths are early signs of severe behavioral inhibition (sometimes also termed anxiety proneness or trait anxiety), and parents' own anxiety (see review, Silverman \& Moreno, 2005; Beidel \& Turner; Shamir-Essakow, Ungerer, \& Rapee, 2005). Briefly, children with behavioral inhibition are often described as fearful and avoidant when confronted with new objects and unfamiliar situations (Kagan, Reznick, Clarke, Snidman, \& Garcia-Coll, 1984) and in such situations they are reported to display higher heart rates and also less heart rate variability than children without behavioral inhibition (Kagan, Reznick, \& Snidman, 1988).

Overall what seems to be inherited is an anxiety proneness per se and, for a specific phobia (or any anxiety disorder) to develop, an interplay of complex environmental factors seems to be necessary. Psychological models, mainly from learning theory are presented next to complement the picture on the acquisition of fear, phobia and anxiety disorders.

\subsection{Psychological models}

Although several psychological theories have been put forward as important in the acquisition and maintenance of fear and specific phobia (e.g., two factor theory, by Mowrer, 1939;1956), the integrative model, on the three pathways to fear acquisition, proposed by Rachman (1977) seems to date to 
be the most influential and robust at present (Beidel \& Turner, 2005; Silverman \& Moreno, 2005). The major pathways to fear acquisition are direct conditioning experiences, indirect vicarious exposure (observational learning) and transmission of information and instruction. Rachman (1977) suggests that the latter two fear acquisitions can take place even without prior direct contact with the fear stimuli.

Briefly, in conditioning theory it is assumed that fears are acquired and further, that neutral stimuli that are associated with a fear or pain (an aversive event), in themselves develop fearful qualities (i.e., they become conditioned stimuli). According to the conditioning theory, fears are more quickly learned if the pairings are frequent, intense, and if the stimulus resembles the original unconditional stimulus (UCS) (Rachman, 1977).

In observational learning, mainly from the work by Albert Bandura (Bandura, Grusec, \& Menlove, 1967; Bandura \& Menlove, 1968) and experimental animal studies, fears are believed to be acquired by children observing another person - a peer, parent or relative - being afraid. Interestingly, it is proposed that this fear acquisition can be very subtle, as observed passive avoidance of a fearful situation by a significant person can lead to fear development in children (Beidel \& Turner, 2005).

In the third pathway on fear acquisition, Rachman (1977) proposed that transmission of information and/or instruction is significant, for example, information given by parents, peers or significant others. The evidence for this type of learning is more based on common sense than data (Rachman, 1977), however, subsequently studies have emerged that lend support to this mechanism of learning. For example, in a study by Barrett, Rapee, Dadds, \& Ryan (1996), children with anxiety disorders were presented with stories about ambiguous situations. Interestingly, when the children were asked what they would do, they generally answered in terms of approach behaviors to the various situations. However, when the same stories were presented in the presence of the parents and discussed with them, the children, after parental instruction statements, generally changed to an avoidance behavior style (Barrett et al., 1996).

Conditioning models, as well as Rachman's integrative model, have in turn been criticized for failing to provide a comprehensive account of the onset of fears and phobias, with the argument that reported experimental and clinical findings are more adequately accounted for by a nonassociative model, thus suggesting a fourth pathway (see reviews, Menzies \& Clarke, 1995; Poulton \& Menzies, 2002). Briefly, the non-associative model suggests that some fears (e.g., heights, water, spiders, strangers and separation) are biologically determined, and as such are passed down from our ancestors to increase our chances of survival. Accordingly, these types of fears emerge spontaneously without prior associative learning experiences, whether direct or indirect (Poulton \& Menzies, 2002). Along similar lines, Öhman and Mineka (2001) proposed a fear module, representing an evolved 
adaption, based on four principles: 1. In all primates, the fear module is activated by specific fear relevant stimuli, which are likely to have an evolutionary origin (e.g., spiders, snakes); 2 . The fear module automatically elicits a response in the above situation; 3. Once the fear module is effectively activated, the fear is hard to control by cognitive means; 4 . The fear module is interconnected to the neural circuitry of the amygdala. The main point is that evolutionary fear-relevant stimuli are thought to trigger the fear module and that the situation need only be mildly aversive. Several theorists have in turn criticised the non-associative account. The main criticism put forward is that the theory is based on negative observational findings (i.e., a lack of a learning history in the acquisition of child phobia) and that it does not take into account children's developmental level or the situation at hand (e.g., novelty, aversiveness and unpredictability) (Muris, Merckelbach, Jong, \& Ollendick, 2002). 


\section{Specific phobias}

\subsection{Diagnosis and assessment}

Some childhood fears can be so problematic because of their intensity, persistence and interference in normal functioning, that they meet criteria for a specific phobia in the Diagnostic and Statistical Manual for Mental Disorders (DSM-IV; American Psychiatric Association, 1994) (King, Muris, Ollendick, \& Gullone, 2005). The diagnostic criteria for a specific phobia are listed in Table 1, together with the five subtypes of phobias that are differentiated in the DSM-IV (APA, 1994).

Table 1. DSM-IV diagnostic criteria for Specific Phobia

A. Marked and persistent fear that is excessive or unreasonable, cued by the presence or anticipation of a specific object or situation (e.g., animals, flying).

B. Exposure to the phobic stimulus almost invariably provokes an immediate anxiety response, which may take the form of a situationally bound or situationally predisposed Panic Attack. Note: In children, the anxiety may be expressed by crying tantrums, freezing, or clinging.

C. The person recognizes that the fear is excessive or unreasonable. Note: In children, this feature may be absent.

D. The phobic situation(s) is avoided or else endured with intense anxiety or distress.

E. The avoidance, anxious anticipation, or distress in the feared situation(s) interferes significantly with the person's normal routine, occupational (or academic) functioning, or social activities or relationships or there is a marked distress about having the phobia.

F. In individuals under age 18, the duration is at least 6 months.

G. The anxiety, Panic Attacks, or phobic avoidance associated with the specific object or situation are not better accounted for by another mental disorder, such as Obsessive-Compulsive Disorder (e.g., fear of dirt in someone with an obsession about contamination), Posttraumatic Stress Disorder (e.g., avoidance of stimuli associated with a severe stressor), Separation Anxiety Disorder (e.g., avoidance of school), Social Phobia (e.g., avoidance of social situations because of fear of 
embarrassment) or Panic Disorder with Agoraphobia or Agoraphobia without a history of Panic Disorder.

\section{Specify type}

Animal Type: If fear is cued by animals or insects. This subtype generally has a childhood onset.

Natural Environment Type: If the fear is cued by objects in the natural environment, such as storms, heights or water. This subtype generally has a childhood onset.

Blood-Injection-Injury Type: If the fear is cued by seeing blood or an injury or by receiving an injection or other invasive medical procedure. This subtype is highly familial and is often characterized by a strong vasovagal response.

Situational Type: If the fear is cued by a specific situation such as public transportation, tunnels, bridges, elevators, flying, driving or enclosed places. This subtype has a bimodal age onset distribution, with one peak in childhood and another peak in the mid-20s. This subtype appears to be similar to Panic Disorder with Agoraphobia in its characteristic sex ratios, familial aggregation pattern, and age at onset.

Other Type: If the fear is cued by other stimuli. These stimuli might include the fear or avoidance of situations that might lead to choking, vomiting, or contacting an illness; "space" phobia (i.e. the individual is afraid of falling down if away from walls or other means of physical support); and children's fears of loud sounds or costumed characters.

In contrast to previous editions of the DSM, the fourth edition acknowledges the developmental nature of children and the developmental course of fears (Ollendick, Hagopian, \& King, 1997), thus many of the criteria have a separate note for children. Importantly, one criterion recognizes that children may express their fears in childhood ways as crying, tantrums, freezing or a clinging behavior. A second criterion is that children need not recognize the unreasonability of their fear, and a duration criterion of six months has been incorporated for children less than 18 years of age.

To arrive at the above specific phobia diagnosis or other childhood psychiatric disorders in children and adolescents, usually some type of assessment instrument is used. Often in clinical research settings these are based on structured or a semi-structured diagnostic interview for DSM-IV. One such instrument that has frequently been used to assess anxiety disorders in children is the Anxiety Disorders Interview Schedule for Children, child and parent versions (ADIS-C/P; Silverman \& Albano, 1996). This instrument's popularity probably stems in part from reports of good to excellent test-retest reliability (Silverman, Saavedra, \& Pina, 2001), and also good to excellent inter-rater reliability reports, outside the country of origin (Öst, Svensson, Hellström, \& Lindwall, 2001). For the section on specific phobia, in the ADIS-C/P, children and parents are asked in separate 
interviews to rate fear and avoidance, and interference in the child's daily life, on a rating scale of $0-8$ (with the aid of a visual analogue scale, pictured as a feelings thermometer). Taken together, the ratings from the child and parents interview respectively aid the clinician in deciding if the child fulfills the criteria for a specific phobia diagnosis. To this end a cut-off score of 4 on the 0 to 8 scale, a moderate degree of impairment, is frequently used as an indication of a diagnosis. Other information from the instrument includes the onset and course of the phobia.

Other assessment instruments include child self-report and parent report of the child's fears and anxiety to tap into the cognitive, behavioral, subjective or physical domains. A frequently used self-report instrument to assess for specific phobia in youths is the Fear Survey Schedule for Children-Revised (FSSC-R; Ollendick, 1983). The FSSC-R consists of 80 items assessing a broad range of fears out of which five common fear factors emerge: fear of danger and death, failure and criticism, the unknown, small animals and medical fears (Ollendick et al., 1983; Silverman \& Moreno, 2005). The FSSC-R has to date been extensively tested for reliability and validity and there are extensive normative data available (see Beidel \& Turner, 2005), also the instrument seems to have good discriminant properties to differentiate children with different types of specific phobias (Beidel \& Turner, 2005; Weems et al., 1999).

A newer instrument in frequent use to assess for symptoms of general childhood anxiety is the Multidimensional Anxiety Scale for Children (MASC; March et al., 1997). The MASC consists of 39 items that sum up to a total anxiety score and four factor scores; social anxiety, physical symptoms, harm/avoidance and separation/panic factors. Recently Baldwin and Dadds (2007) also introduced a parent version of the MASC (MASC-P) as a complement to the child version. Normative data on the MASC-P are available for a Swedish sample of school children aged 8 to 16 years, with reported Cronbach's $\alpha=0.88$ (Ek \& Israelsson, 2008).

As a complement to the diagnostic assessment interview, child-report and parent-report, behavioral assessment is used to assess phobic severity. One example of this is the behavioral approach test (BAT), which has been used in several studies (King, Ollendick, \& Murphy, 1997; Öst et al., 2001). Typically the behavioral tasks are set up for each specific phobia with gradually more difficult steps to be reached within a specified time limit, e.g. two minutes. Thus, a child who is afraid of dogs might be asked to approach a dog and to keep approaching as far as they can with a high-end goal of patting the dog on the head. A child who is afraid to ride an elevator might similarly be asked to approach the elevator, to enter, with the last step being to ride up and down a number of floors. Importantly, the child always decides when to stop the behavioral task. Outcome measures consist of accomplished steps (e.g., distance of approach to the feared object in meters, or sound intensity, or time). The proposed advantages with BATs are that 
they give a concrete measure of the child approach behavior, and are less susceptible to confounds such as social desirability, expectations and therapist demand (Beidel \& Turner, 2005).

\subsection{Prevalence}

Epidemiological studies on the prevalence of psychiatric disorders in children and adolescents have reported quite high overall prevalence rates, ranging from $17.5 \%$ to $22.5 \%$ (Anderson, Williams, McGee, \& Silva, 1987; Bird et al., 1988; Costello et al., 1988; McGee et al., 1990; Steinhausen, Metzke, Meier, \& Kannenberg, 1998; Verhulst, Ende, Ferdinand, \& Kasius, 1997; Wittchen, Nelson, \& Lachner 1998), with anxiety disorders being frequently prevalent (McGee et al., 1990; Steinhausen et al., 1998). Worldwide prevalence rates for specific phobia in youths, based on parent and/or child reports, are reported to range between 2.3 and 9.2\% (Table 2). Similarly, the prevalence of parent reported specific phobias in a sample of 8 to 9 year old Swedish twins was also within this range, $8.65 \%$ (Lichtenstein \& Annas, 2000). In contrast, among children seeking treatment for anxiety disorders, specific phobias have been reported as the primary diagnosis in 17 to $42 \%$ of the cases (Last, Perrin, Hersen, \& Kazdin, 1992; 1996). The most common subtypes of specific phobia are reported to be animal and natural environment type (Essau, Conradt, \& Petermann, 2000).

Table 2. Prevalence rates for Specific Phobia in youths

\begin{tabular}{llccr}
\hline Study & Country & N & Age Range (yrs) & Rate \\
\hline Anderson et al. (1987) & New Zealand & 782 & 11 & $2.4 \%$ \\
Bird et al. (1988) & Puerto Rico & 777 & $4-16$ & $2.6 \%$ \\
Costello et al. (1988) & United States & 789 & $7-11$ & C: $6.7 \%$ \\
& & & & P: $3.0 \%$ \\
McGee et al. (1990) & New Zealand & 943 & 15 & $3.6 \%$ \\
Verhulst et al. (1997) & Netherlands & 272 & $13-18$ & C: $4.5 \%$ \\
& & & & P: $9.2 \%$ \\
Steinhausen et al. (1998) & Switzerland & 379 & $7-16$ & $5.8 \%$ \\
Wittchen et al. (1999) & Germany & 3021 & $14-24$ & $2.3 \%$ \\
Essau (2000) & Germany & 1035 & $12-17$ & $3.5 \%$ \\
\hline Note: C = Child; P = Parent & & & &
\end{tabular}




\subsection{Age of onset}

Overall, specific phobias (all subtypes) are reported to have an early onset in life, usually before reaching 10 years of age (Essau, 2000; Kessler et al., 2005; Last et al., 1992). In a large clinical sample of children, aged 4 to 18 years, referred for psychiatric evaluation of major psychopathology, simple phobia was reported to have an early onset (mean 4.5 years; Biederman et al., 1997). From adult reports the mean age of onset for various specific phobias is reported to be 7.2 years, and the duration of the phobia, as reported from adults entering treatment, to be between 6 and 39 years (Öst, 1987; 1989). This suggests that there is some continuity from childhood to adulthood.

\subsection{Gender}

Overall it seems that males and females are affected in equal frequency in having at least one lifetime disorder when any substance disorder and other mental disorders are taken into account (38.3\% and 39.4\%, respectively) (Wittchen, Nelson, \& Lachner 1998). However, whereas males more often meet criteria for a substance disorder, females more often meet criteria for affective, anxiety, somatoform and eating disorders (Wittchen et al., 1998). The ratio on lifetime risk for any anxiety disorder was reported to be 1.6:1 female to male (Kessler et al., 2005). This gender difference is present, across most of the studies, on the prevalence rates of specific phobias in children and adolescents presented in Table 2. More specifically, the gender ratio is reported to be 0.6:1 and 1:2.9 male to female, respectively (Anderson et al., 1987; McGee et al., 1990), and lifetime prevalence of specific phobia to be $1.2 \%$ in males and 3.3\% in females (Wittchen et al., 1998).

\subsection{Comorbidity}

Comorbidity rates for "any" psychiatric disorder were reported to be $55 \%$ in 11 year old children with a primary diagnosis (Anderson et al., 1987), 46\% in 4 to 16 year old children (Bird et al., 1988) and 47\% in 13-18 year old youths (Verhulst et al., 1997). The highest proportion of comorbidity was accounted for by the various anxiety disorders (Steinhausen et al., 1998).

Interestingly, a study by Kendall, Brady and Verduin (2001) examined the impact of comorbidity on treatment outcome, in children aged 8 to 13 years with anxiety disorders, and found that $79 \%$ of the children had at least one comorbid diagnosis at pretreatment. The most frequently reported comorbid diagnoses were simple phobia, social phobia and generalized 
anxiety disorder, and pre-treatment comorbidity was reported not to be associated with differences in treatment outcome (Kendall et al., 2001).

Epidemiological studies specifically examining the comorbidity of specific phobia with other disorders are scarce. One such study, however, reported that $47.2 \%$ of the children suffered from an additional anxiety disorder, $36.1 \%$ from depressive disorders, 33.3\% from somatoform disorders and $8.3 \%$ from substance use disorders (Essau et al., 2000). In contrast, more studies can be found on clinical samples of children with a primary specific phobia disorder and these report comorbidity rates of between 42 and $75 \%$, wherein an additional anxiety disorder is also found to be most common (Last et al., 1992; Silverman et al., 1999; Öst et al., 2001).

\subsection{Clinical course}

There is some support for the belief that psychopathology in children remains fairly stable, when it is left untreated. For example, one study found that 7-11 year old children with a disorder at time 1 had an increased risk of adolescent disorder at time 2, five years later (Costello, Angold, \& Keeler, 1999). Some researchers have suggested that the stability is greater for behavioral disorders than anxiety disorders (Cantwell \& Baker, 1989). This having been said, research on the natural course of specific phobias per se in children and adolescents is to date meager (Silverman \& Moreno, 2005).

The information available is mostly from clinically referred children engaging in treatment. For example, in a two year follow-up study, $80 \%$ of children $(\mathrm{N}=62 ; 6$ to 15 years old) who had received treatment for their phobia were overall symptom free although $7 \%$ were reported to still have a severe phobia (Hampe, Noble, Miller, \& Barrett, 1973). Limitations in this study include the lack of child report and no formal diagnostic interview being used. Another study used a prospective design and examined the course and outcome of anxiety disorders in clinically referred children. Interestingly specific phobia was found to have the poorest rate of recovery (Last et al., 1996), others have found impairment in routine activities and leisure time activity restrictions (Essau et al., 2000; Wittchen et al., 1998).

Information from epidemiological research on the prevalence of anxiety disorders and specific phobias in adults has reported these to be relatively high (Kessler et al., 2005; Regier, Narrow, \& Rae, 1993). As specific phobias have been reported to have an early onset (Öst, 1987), it seems likely that there is some continuity into adulthood, and a clinical impression is that phobias that persist into adulthood infrequently go into remission. Researchers in the field are now pursuing the possibility that specific phobias might be a gateway to other anxiety disorders and even depression. If this is the case, then it is even more worrying that only a small portion of 
children and adolescents with specific phobias seek professional help (Essau et al., 2000). 


\section{Parenting behaviors and childhood anxiety}

Parenting behavior is an interesting field of research which advanced substantially in the late 1970s with the introduction of the now well known Parental Bonding Instrument (PBI) by Parker, Tupling, and Brown (1979). In this self-report questionnaire, adults are asked to recall their parents' parenting behaviors up to the age of 16 years. Two broad dimensions are derived from this instrument - care giving and overprotection - with the possibility of combining the scale to generate four types of behaviors, wherein high care-low protection is seen as being optimal (Parker et al., 1979). The instrument has in later years been modified to obtain parents' current perceptions of their own parenting behaviors also, in order to examine if parental behaviors might be transferred from one generation to the next.

In more recent analytical work on responses to the PBI for different samples, a three factor model has been reported to produce a better fit to the data (e.g., care, overprotection and authoritarianism) (Chambers, Power, Loucks, \& Swanson, 2000; Cox, Enns, \& Clara, 2000; Heider et al., 2005; Kendler, 1996). In contrast, Uji, Tanaka, Shono, and Kitamura (2006) found a four factor solution (care, indifference, overprotection and encouragement of autonomy) to be psychometrically superior to a three factor solution in a Japanese study, for both adult and child generations.

\subsection{A genetic-epidemiologic perspective of parenting}

The role that genetic and environmental factors may play in the elicitation and provision of parenting behaviors is seen as an important perspective for studying the relation between parenting and later psychopathology (Kendler, 1996). Several twin studies, using large samples for their analyses, have suggested genetic influences in both the provision and elicitation of parenting from a parent perspective (Kendler, 1996; Knafo \& Plommin, 2006), a child perspective (Harlaar et al., 2007; Kendler, 1996), as well as common environmental factors and nonshared environmental factors (Harlaar et al., 2007), probably reflecting characteristics of the mothers studied (Forget-Dubois et al., 2007).

In a longitidinal twin study, prosocial behavior in children was assessed (e.g., behavior intended to benefit others) as well as parenting (parental 
positivity and negativity), as rated by parents at ages 3,4 and 7 years and by teachers at age 7 years. In brief, genetic factors were reported to mediate the negative correlation between prosocial behavior in the child and parental negativity, whereas shared environment effects contributed most to the positive relationship between prosocial behavior and parental positivity (Knafo \& Plommin, 2006).

Moreover, Kendler (1996) examined the role of genetic and environmental factors in influencing parenting (with the PBI) from multiple perspectives: Parents reporting on the parenting of their twins; twins reporting on their parents' parenting as children; one twin reporting on the parenting received by the co-twin as a child, and twins' own parenting of their children. Overall, individual differences in the level of warmth displayed by parents toward their children were reported to be influenced not only by parental temperament characteristics but also, within a family, the offspring's characteristics (both in part under genetic control). Child characteristics are further thought to influence parent behavior directly (e.g., by being more or less "lovable"), and indirectly to influence the way a child perceives this behavior (Kendler, 1996). The other two factors, parental protectiveness and authoritarianism, were found to be little influenced by genetic factors but substantially affected by the parent's family background, and suggested to be associated with social and religious attitudes learned from the family of origin (Kendler, 1996).

As discussed by Knafo and Plomin (2006), limitations of these twin studies include the lack of a multi-assessment approach. The use of selfreport measures, although it is understandable considering the large samples involved, might give rise to biased information favoring the heritability factor as opposed to data from observers, on a narrower spectrum of behaviors. Another limitation could be that parenting twins and being part of a twin family is more of a challenge, and different to single child parenting, hence results from families with twins might not be readily generalized to families outside the twin population. Also, as noted by the authors, in the Kendler study (1996) only female twins were studied and in the Knafo and Plomin study (2006) only mothers.

In summary, twin studies suggest that both genetics and the environment contribute to individual differences in parenting. Most stress the importance of parents' and children's temperamental traits which are proposed to be under partial genetic control. However, whereas some parenting behaviors like warmth seem to be more attributed to genetic factors (i.e., heritability), protectiveness and an authoritarian parenting appear primarily to be due to family environment. Also, results from several twin studies are consistent with more modern views of parenting where children are seen as active participants in the parent-child relationship (Kendler, 1996; Knafo \& Plomin, 2006). 
However, criticism has also been directed to studies on behavioral genetics. One main criticism is that the reciprocal influence parents and children are thought to have on one another (i.e., through a feed-back loop system) has largely been ignored, thereby seriously underestimating parenting effects (Maccoby, 2000). Moreover, Maccoby (2000) urges researchers to give up the effort to partition the causal factors influencing children's development into two separate components of nature and nurture, as both seem to be inextricably interwoven from birth to mature age, thus efforts should be concentrated on the ways in which they joinly function.

\subsection{Perceived poor parenting and anxiety in children}

More recently, focus has been directed to enquire about the relationship between parental behaviors and the development of childhood anxiety, the results of which have been summed up in several reviews (Bögels \& Brechman-Toussaint, 2006; Rapee, 1997; Wood, McLeod, Sigman, Hwang, $\& \mathrm{Chu}, 2003)$. Briefly, it is tentatively concluded that there is little evidence that a general parenting style per se is related to children's trait anxiety (Wood et al., 2003). However, more specific parental controlling behaviors (perceived and maybe also actual) seem to be associated with child fear and anxiety (Bögels \& Brechman-Toussaint, 2006; Ollendick \& Horsch, 2007; Rapee, 1997), shyness and child anxiety disorders (Wood et al., 2003).

Along similar lines, it was reported from a longitudinal study, in 14 to 17 year old adolescents (at baseline), that perceived overprotective and rejective parenting styles were associated with the development of social phobia in youth (Lieb et al., 2000). A meta-analytic study also indicated that perceived less affection and more control was related to phobic disorders, in comparison with "healthy" controls (Gerlsma, Emmelkamp, \& Arrindell, 1990). Importantly, poor parental behaviors have also been found to be related to poor outcome following treatment, irrespective of treatment type and severity (Chambers, Power, \& Durham, 2004).

Some interesting work has been conducted using direct observational methods where parent-child interactions have been studied under different task contingencies (e.g., conversational, cognitive) (Hudson \& Rapee, 2001; Moore, Whaley, \& Sigman, 2004; Shortt, Barrett, Dadds, \& Fox, 2001; Siqueland, Kendall, \& Steinberg, 1996). The reported findings are striking, that mothers of anxious children are less warm, grant less autonomy, are more negative and involved, and when the children are anxious and stressed, mothers become more protective, in comparison with mothers of nonclinical children. Children with anxiety disorders have in turn been reported to rate their parents as less accepting (Siqueland et al., 1996), and been found to interpret ambiguous situations as more threatening than children in a control group (Shortt et al., 2001). Others have used samples of non- 
clinical school children, and found that perceived anxious rearing behaviors are associated with parental control and with child symptoms of generalized anxiety disorder, separation anxiety disorder and environmental-situational phobia in children (Muris \& Merckelbach, 1998).

\subsection{Theory}

In current models of anxiety, it is suggested that parental rearing behaviors make a unique contribution to both the development and the maintenance of anxiety disorders in children and adolescents. In this respect, parental over-control is thought to be most detrimental for the child in two ways. First, with such a parenting style, what seems to be communicated to the child is the presence of a constant threat, resulting in an increase in hyper vigilance and fear. Secondly, the child is given a limited opportunity to approach situations on their own which in turn hinders new learning in the domains of personal competency, mastery and control (Barlow, 2002; Chorpita, Brown, \& Barlow, 1998; Rapee, 1997; Vasey \& Dadds, 2002). Although there now seems to be considerable support and consensus that parental over-control behavior is associated with child anxiety, the direction of effect of this relationship is unclear (see review, Bögels \& BrechmanToussaint, 2006). Children are increasingly viewed as highly interactive from birth and in this perspective also capable of eliciting overprotection from their parents in anxiety provoking situations. 


\section{Parent-child agreement on child diagnosis}

\subsection{Agreement on anxiety disorders}

Reliability measures on semi-structured diagnostic instruments like the ADIS-C/P (Silverman \& Albano 1996), using test-retest, have been reported to show good to excellent reliability for parents and children respectively (Silverman et al., 2001), and for younger and older children (Silverman \& Eisen, 1992). However, when it comes to agreement between parents and children on child diagnoses, across a range of different diagnostic instruments, the reported agreement is generally found to be poor (Choudhury, Pimentel, \& Kendall, 2003; Comer \& Kendall, 2004; Edelbrock, Costello, Dulcan, Conover, \& Kala, 1986; Grills \& Ollendick, 2003; Rapee, Barrett, Dadds, \& Evans, 1994). This disagreement also seems to be more broadly present around referral problems at treatment entry. For example, in a study by Yeh and Weisz (2001), 381 clinically referred outpatient children, aged 7 to 18 years, and their parents were asked independently to list the child's target problems. The authors reported that more than $60 \%$ of the parent-child dyads did not agree on even a single problem the child needed help for. Even when broader category matches were used it was found that still more than one-third of the dyads did not agree on even a broad problem area (Yeh \& Weisz, 2001). This has likewise been reported to be the case across both internalizing and externalizing disorders (Seiffge-Krenke \& Kollmar, 1998; Yeh \& Weisz, 2001).

Research with a focus on parent-child agreement on specific phobia in children and adolescents is much more meager. The few studies found on this, however, have reported likewise poor parent-child agreement, with kappa values ranging from 0.23 to 0.35 for a principal diagnosis or a specific phobia present anywhere in the diagnostic profile (Choudhury et al., 2003; Grills \& Ollendick, 2003; Rapee et al., 1994).

\subsubsection{Child factors}

A few child factors have been examined to see if they might be influencing the low parent-child agreement reported on child diagnosis and symptomatology. As is common in many studies within the psychological 
field, most researchers have examined the variables of child age and gender. Briefly, the results from these have been contradictory, with some studies reporting parent-child agreement to be stronger in older children (Edelbrock et al., 1986; Grills \& Ollendick, 2003; Rapee et al., 1994; Reich, Herjanic, Welner \& Gandhy, 1982), in younger children (Safford \& Kendall, 2005), and some reporting the agreement not to be age dependent (Jensen et al., 1999). As to child gender, two studies reported overall non-significant findings (Choudhury et al., 2003; Engel, Rodrigue, \& Geffken, 1994). In contrast, one study found parent-daughter agreement to be stronger than parent-son agreement (Safford \& Kendall, 2005), and yet a fourth study reported parent-son agreement to be significantly stronger for the diagnoses of social phobia and separation anxiety (Grill \& Ollendick, 2003). Several explanations might lie behind the above reported discrepant results. For example the use of different diagnostic instruments across the studies whether the same or separate interviewers conducted the assessment with the parents and children and if the unit of analysis is at the symptomatic or at the diagnostic level of the anxiety. In the latter case, parent-child agreement has been found to be stronger at the symptom level than at the diagnostic level for separation anxiety disorder, social phobia and generalized anxiety disorder (Comer \& Kendall, 2004).

Other factors that have been examined in children and adolescents are social desirability (Di Bartolo, Albano, Barlow, \& Heimberg, 1998), selfesteem and self-representation (Elliott, 1982) and motivation (Battjes, Gordon, O'Grady, Kinlock \& Carswell, 2003; Darling, Hames, \& Cumsille, 2000). However, social desirability is the only factor that has been examined in the context of children presenting with an anxiety disorder (Di Bartolo, Albano, Barlow, \& Heimberg, 1998). In the study of Di Bartolo et al. (1998), parent-child agreement was assessed on social anxiety symptoms in children and adolescents presenting with a principal social phobia diagnosis. Although it was reported that there were no significant differences between parent and children's ratings of the children's social fears, parents reported significantly greater social avoidance in their children than did the children themselves. Interestingly, children's score on social avoidance was negatively associated with scores related to concerns on social desirability (Di Bartolo et al., 1998).

\subsubsection{Parental psychopathology}

Several studies have suggested that general psychopathology in parents has an influence on parents' report of their children's anxiety and depression (Berg-Nielsen, Vika, \& Dahl, 2003; Krain \& Kendall, 2000; Renouf \& Kovacs, 1994). Often the direction of this influence is positive, that is, the higher the level of parental psychopathology, the more symptoms are 
reported in the children, resulting in poorer parent-child agreement. It is noteworthy that the bulk of study reports come from mothers, as they are most often the parent to accompany the child to the clinic. From this, higher maternal distress (Garber, Van Slyke, \& Walker, 1998), stress (Martin, Ford, Dyer-Friedman, Tang, \& Huffman, 2004), and depression (Berg-Nielsen et al., 2003; Krain \& Kendall, 2000; Renouf \& Kovacs, 1994), are reported to be associated with increased reports of internalizing and externalizing problems in children, and more so than the children themselves report. One study, which included both parents, reported that both maternal and paternal scores on depressive symptoms were significant predictors of parent report of anxiety in girls (Krain \& Kendall, 2000). Although two recent reviews failed to find a consistent pattern (De Los Reyes \& Kazdin, 2005; Grills \& Ollendick, 2002), future research might examine parent-child discordance on child diagnosis, with parents who have themselves been clinically assessed with a sound diagnostic instrument for further clarification. If general psychopathology and diagnoses in the parents is differentially influencing what the parents are reporting in the child diagnostic interview, in comparison with parents without these problems, it seems important to have this prior understanding with us in the assessment and treatment phase. 


\section{Randomized treatment studies of specific phobias in children}

Many randomized treatment studies have been conducted on adults suffering from specific phobias. In a recent meta-analysis, an initial search was reported to yield 988 articles (Wolitzky-Taylor, Horowitz, Powers, \& Telch, 2007). From this 33 randomized treatment studies were quantitatively analyzed, and the authors reported evidence supporting the superiority of exposure-based treatments over alternative treatment approaches in adults with specific phobias. Further, in-vivo exposure treatments which entail actual confrontation with the phobic object/situation were reported to outperform alternative modes of exposure (e.g., imaginal, virtual reality exposures) at post-treatment.

Similarly, in a very recent review, evaluating the exposure-based onesession treatment (OST; Öst, 1989; see below under cognitive-behavioral treatments), examination of pre- to post-treatment differences revealed significant reduction in ratings of subjective units of distress (SUD), during BAT and on self-report measures of fear (Zlomke \& Davis, 2008). In conclusion, the authors noted that OST continues to be a promising treatment for specific phobias in adults (Zlomke \& Davis, 2008) and OST is presently the treatment of choice in adult specific phobias.

Many case and clinical studies have been conducted in children with fears and some on specific phobias, but in comparison with adults randomized controlled treatment studies are scarce. A literature search (using common data bases and references sections from reviews) yielded 13 randomized controlled studies, conducted between 1970 and 2001. A list summarizing these studies is presented in Table 3 , showing country of origin, sample sizes and ages, type of phobia, treatment, number of sessions and hours, attrition, outcome measures, clinical significance and follow-up data, where this has been reported. Overall, the active treatment condition in these studies was based on behavioral or cognitive-behavioral principles. This was similarly reported to be the case in a recent meta-analysis over 24 studies on psychotherapy of childhood anxiety disorders, where $90.5 \%$ of the studies used a mixture of exposure techniques, $66.7 \%$ cognitive restructuring strategies, $52.4 \%$ relaxation techniques and $38.1 \%$ positive self-talk (InAlbon \& Schneider, 2007). 


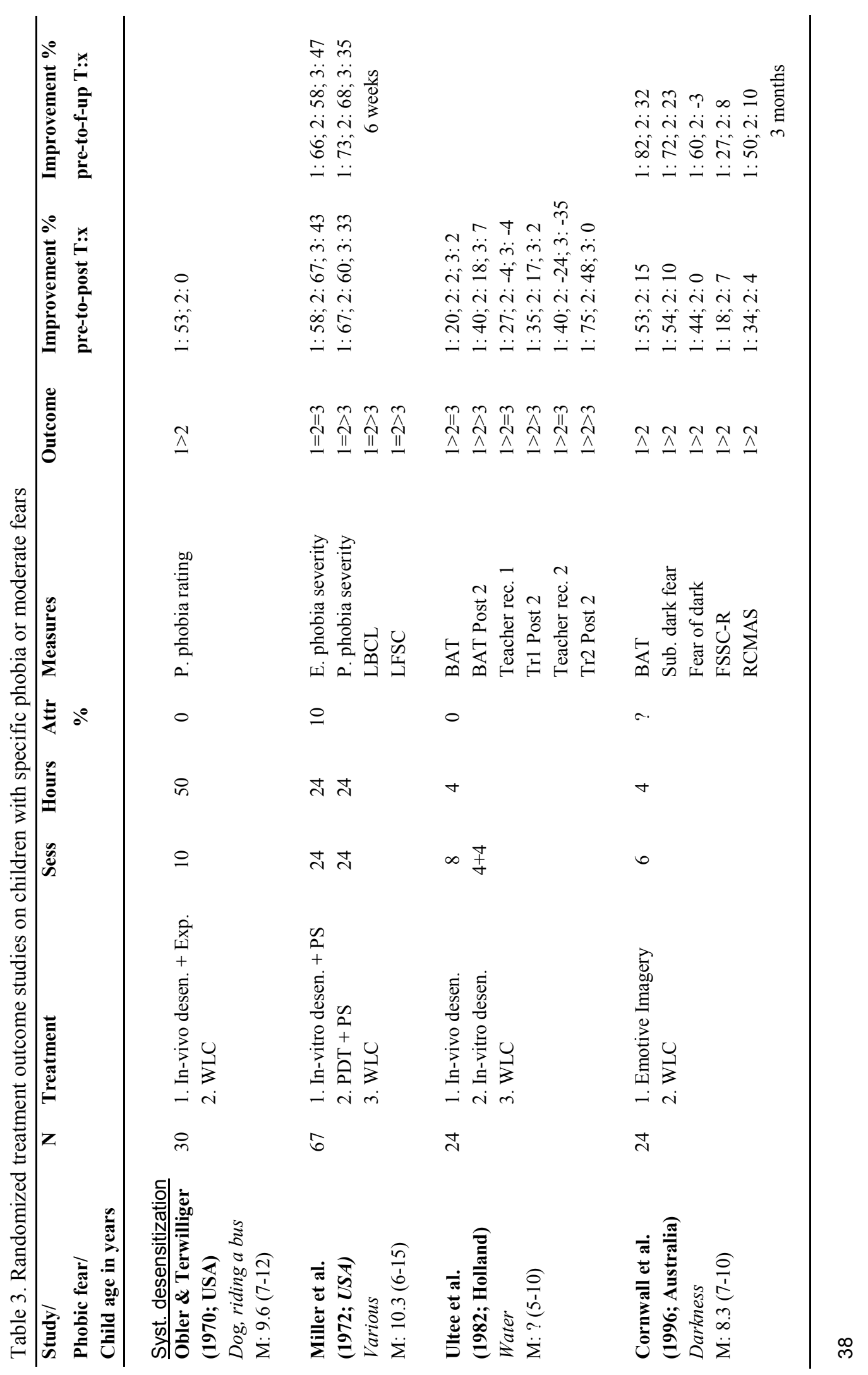




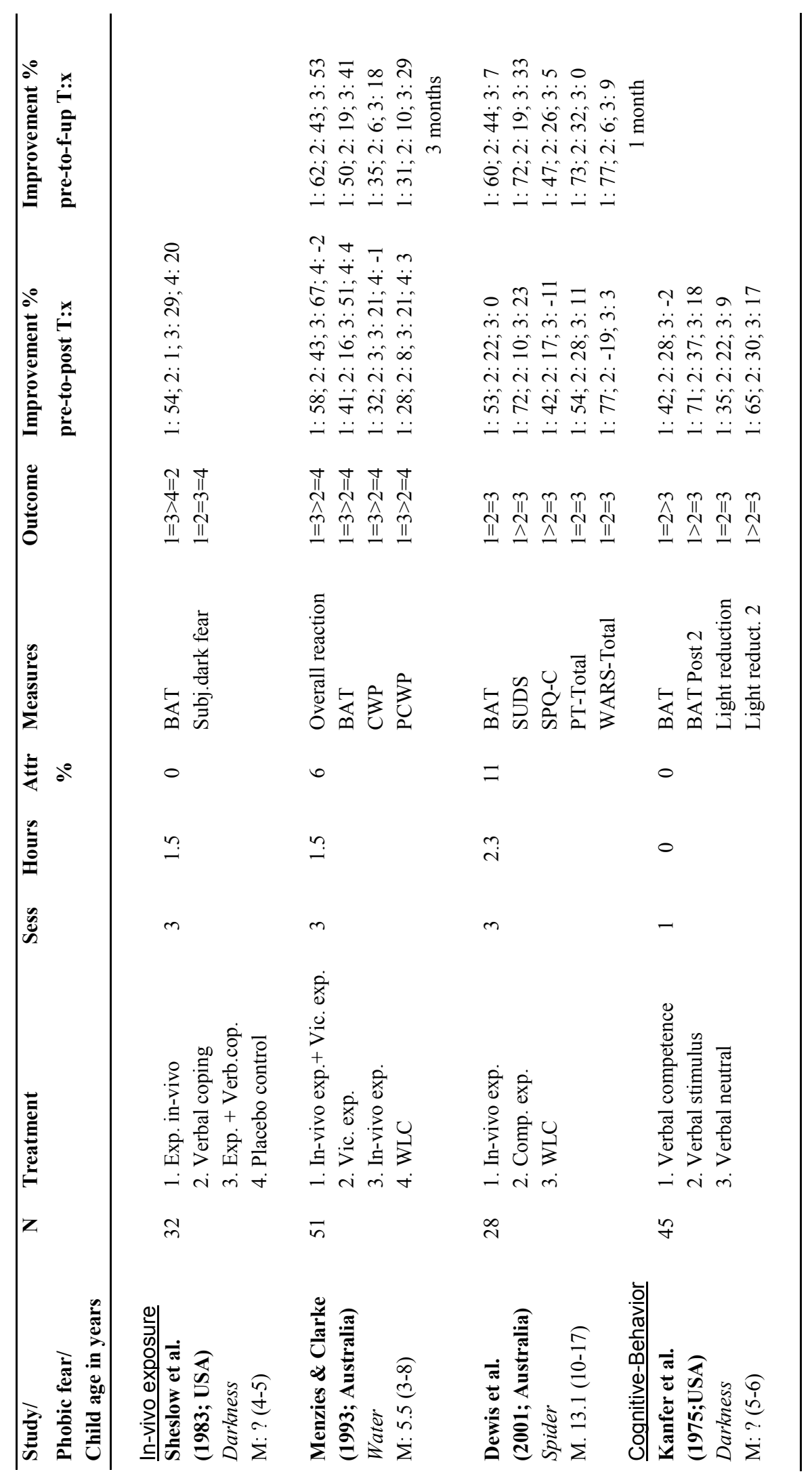




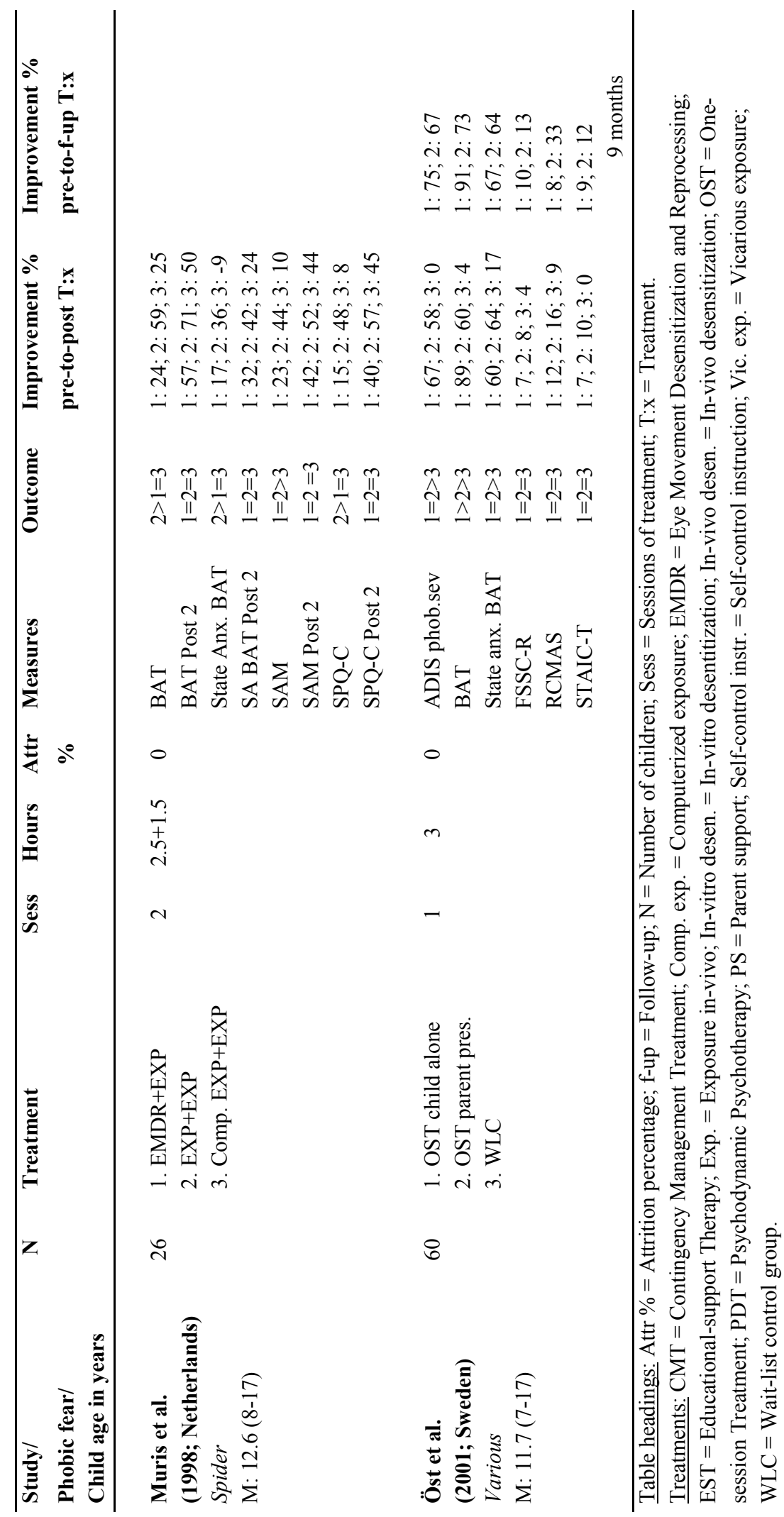




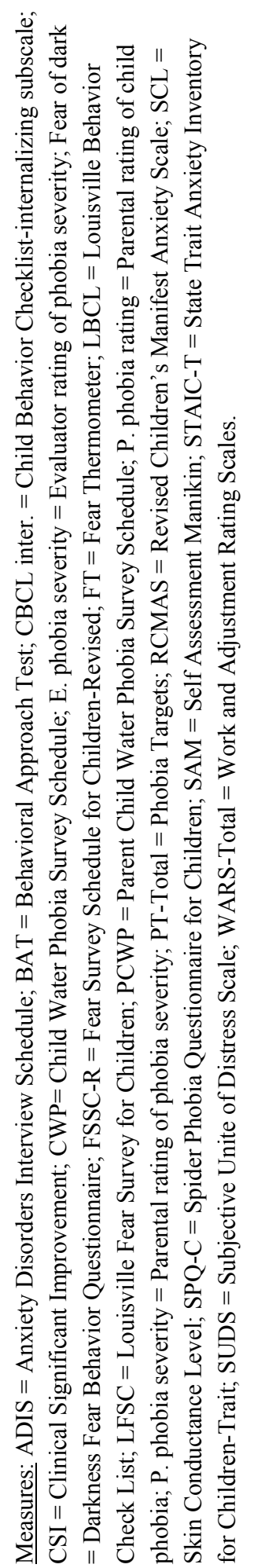




\subsection{Behavioral treatments}

The 13 randomized controlled studies on children with specific phobia or moderate fears presented in Table 3 are reviewed in some more detail below, starting with the study by Obler and Terwilliger (1970) and closing with the study by Öst et al. (2001).

\subsubsection{Systematic desensitization and its variations}

Systematic desensitization is viewed as a behavioral intervention, grounded in classical conditioning theory, and developed by Joseph Wolpe (1958). Briefly, a response is initially taught, usually some form of relaxation, that is incompatible with the fear. Next, an individual fear-hierarchy is produced, and in the last step a systematic and gradual pairing of the items in the hierarchy (imaginal) with the incompatible response (e.g., deep relaxation) takes place. The rationale is that classically conditioned responses can be unlearned with counter-conditioning interventions, functioning as anxiety inhibitors, with resulting fear reduction. Interestingly, a variation of systematic desensitization was used as realy as 1924, in the pioneering work of Mary Cover Jones. In one, now classical, case study, a real-life exposure, paired with a craving object (food) inducing a positive response, was used to help a very young child overcome an animal fear (rabbit) which had also generalized to other animals (Jones, 1924).

Three randomized controlled group outcome studies were found examining systematic desensitization in children and adolescents with fears severe enough to be classified as phobic. In the first study, by Obler and Terwilliger in 1970, 30 children aged 7-12 years diagnosed with minimal brain dysfunction and a severe phobic disorder (for public buses or dogs), were randomized to a modified version of systematic desensitization, or to a control group matched for age, gender, intelligence and phobia diagnosis. The treatment consisted of a five-hour weekly session over a ten-week period. Prior to exposing children to the real-life fear-inducing stimulus (bus or dog) they were asked to look at pictures or models, as opposed to imagining the stimulus, which, according to the authors, would have been too difficult a task for this sample of children. When the pictures or models were tolerated, the treatment progressed to real-life situations where children were rewarded, first with encouragement and at more advanced stages with more tangible rewards (e.g., toys, books, candy), for approaching and later for staying in a room with a dog or talking to a bus driver. Treatment effectiveness was assessed with a 10-item parent rating scale, consisting of questions on the child's phobic behavior and general functioning in school, with peers and society, at pre- and post-treatment. At pre-treatment, all 
children received a zero on the parent rating scale, on the phobic behavior, which meant that they were either not able to ride a bus or touch a dog. After treatment, all children in the therapy group were reported to be able to ride a bus or touch a dog when accompanied by another person, and significantly more children in the therapy group were also able to do this unaccompanied. The authors also noted that the treatment worked equally well for children both in the high and low-IQ treatment groups (cut-off score of 75). This treatment then seems to show encouraging preliminary results for working with children with neurological impairments and phobias. The study as such lacks a multi-assessment approach, however. There was no report of diagnostic assessment at post-treatment, nor was a follow-up done, so we do not know if the treatment's effects were maintained over time.

In a second study from 1972 (Miller, Barrett, Hampe, \& Noble), 67 children, aged 6-15 years, presenting with a clinical level of various phobias (even school phobia), were randomly assigned to a 2 (two male therapists) $\mathrm{x}$ 3 (three treatment/conditions) factorial repeated-measures covariate design. The treatments were; reciprocal inhibition, psychotherapy, or a three-month wait-list control group. Assessments included a clinical evaluation, parentchild report and a behavioral test, all done at pre- and post-treatment, after wait-list completion, and at a six-week follow-up. The length of treatment was 24 one-hour sessions, three times a week and across eight weeks. The reciprocal inhibition therapy was based on Wolpe's systematic desensitization but here adapted for use with children in which more techniques were added, primarily based on learning principles. This could entail restructuring contingency schedules where parent-child interactions were assessed as reinforcing fear behavior. A concrete example of this is provided for a child with school phobia wherein television was removed during school hours as the child stayed at home. Other techniques could include breathing control techniques or assertiveness training. The desensitization treatment consisted of relaxation and imagining various fear arousing scenes from a fear hierarchy and switching to a pleasant imagination when the child signaled anxiety. The psychotherapy treatment was described as being a play therapy for the younger children, aged 6-10 years, who were seen in a play room, the older children could choose this place or an interview therapy room. The emphasis of the therapy, for all children in this therapy condition, was for children to "talk out" feelings and conflicts. Children were also encouraged to formulate behavioral strategies for coping with stress and affect. Another intervention was aimed at removing secondary gains, where parents were to remove gratifications such as television on school days. For both treatments parents were invited to sessions as necessary. Interestingly, parents with problems unrelated to the child's phobia were offered treatment by a social worker, who was part of the project team. 
Overall the results showed a reduction in the clinical evaluator severity score (ranging from 1 to 7) over time, however there was no therapist effect and no significant differences between treatments and wait-list control. A similar severity score rating on the treated phobia by parent report also failed to reveal a therapist effect. However, a treatment effect was found, where both therapies were more effective in comparison with the wait-list control group, also at follow-up, but there were no significant differences between the two treatment groups. Two parent-report instruments, the Louisville Behavior Check List and the Louisville Fear Survey for Children, measuring children's general tendency to respond to fear, again showed no effect of therapist but overall effects of treatments, where reciprocal inhibition and psychotherapy had significantly lower mean fear scores at post-treatment assessment, and at the six-week follow-up. Also the authors reported that treatment was significantly more successful on the outcome measures for the younger age group (6-10 years), than for the older group of 11-15 year olds.

One advantage with this study is that a multi-assessment approach was used on intake assessment to supplement the parent and child reports. A behavioral fear test, Child's Fear Thermometer and a five-day check with parents to see that the fear was unchanged, a School Behavior Check List, from the child's teacher, and several psychological tests measuring constructs of intelligence. Secondly, the wait-list control group had a waiting period of about three months which meant that this extended over the treatment and follow-up. However, there are also several limitations, some of which the authors themselves point out. First, the primary assessor was not blind to the treatment randomization, which might have biased the results. Second, it is not clear if the behavioral fear test was done at postassessment as there are no separate scores for this. Also, the reported outcome results seem meager in comparison with the reported measurements. These reports might have revealed differences in treatment effects. Also more problematic is the difficulty in neatly separating the two treatments (independent variables) from each other. Both treatments had parental support and incorporated instructions on contingent management procedures for the parents which might be a confound, influencing the outcomes to produce no difference results.

In the third study (Ultee, Griffioen, \& Schellekens, 1982), 24 children aged 5-10 years with a strong fear of water, were randomized to two treatment groups or to a control group. Their fear of water was based on parental judgment and two swimming teachers who, independently of one another, judged the children's anxiety during a simulated swimming lesson. The selected children had a higher mean score on a water avoidance test than a comparable group of non-anxious children. The in-vitro desensitization group was treated with four sessions of gradual imaginal exposure and four sessions of real-life exposure to the feared stimulus, whereas children in the in-vivo desensitization group were treated with eight sessions of gradual 
real-life exposure only. The treatment length was 30-minute sessions, twice weekly for both groups. Assessments points were pre-test, an intermediate test after four sessions (after which both treatment groups had the in-vivo treatment), and a post-test at the end of the treatment. Assessments included a behavior observation record to evaluate the children's avoidance behavior in feared swimming-pool situations, scored independently by two graduate students. There was also a teacher's record, where two swimming teachers rated the children's behavior as they performed various tasks in the swimming pool, and a second teacher's record, where two additional swimming teachers predicted how anxiety would develop in each child from their behavior in the water. These teachers' ratings were also done independently of one another. In comparison of results after the initial four sessions, children in the in-vivo desensitization group showed greater gains than children in the other two conditions. Also there were no significant differences reported between the in-vitro desensitization group and the control group on the above measures. In the comparison of effect after all eight sessions, children in the in-vivo group continued to do better than the other two groups. However, at this time there was also an improvement reported for the in-vitro group, which the authors tentatively interpret as an additional support for the superiority of the in-vivo treatment (children received in-vivo treatment in the last four sessions).

One aspect that is neglected in the discussion is that small numbers of children were included in the three groups; seven, eight and nine respectively. With such small samples, power is generally low, making it difficult to differentiate properly between treatments and/or controls. Low power then could be an explanation for the non-significant difference reported between the in-vitro group and the control group in this study. Also, a criticism that has been raised against using systematic desensitization with children is that it might be developmentally unsuitable, especially training in relaxation, which is seen as fairly demanding and tedious (King, Heyne, Gullone, \& Molloy, 2001).

In summary, Ollendick and King (1998) conclude, in a review of empirically supported treatments for children and adolescents with excessive childhood fears, phobias and other anxiety disorders that imaginal and invivo desensitization treatments have reached the status of probably being efficacious. This was concluded again, in a later review on specific phobias, specifically for behavioral tasks and alleviation of subjective fear (Davis \& Ollendick, 2005). To be considered well established, systematic desensitization would have to be found superior to other psychological interventions in two or more studies conducted by different research teams (Davis \& Ollendick, 2005). 


\subsubsection{Emotive imagery}

Emotive imagery is often described in the literature as a variant of systematic desensitization, sometimes called "narrative story form" desensitization. It was pioneered by Lazarus \& Abramowitz (1962), and used specifically to treat children's phobias and excessive fears (King et al., 2001). Here, instead of inducing relaxation, an imagery eliciting strong positive emotions, such as pride, self-assertion or mirth, is created from children's hero-images. As in systematic desensitization, anxiety items from the fear-hierarchy are then introduced in a gradual way as part of the narrative in "story form".

Only one controlled study examining the efficacy of emotive imagery was found (Cornwall, Spence, \& Schotte, 1996). In this study, 24 children aged 7 to 10 years, who met the DSM-III-R criteria for darkness phobia (APA, 1987), were randomly assigned to either emotive imagery treatment or a wait-list control group. The emotive imagery treatment consisted of weekly sessions spanning over six weeks. Briefly, nine scripts were developed, tapping into a hierarchy of situations related to darkness fears. Attempts were made to personalize the scripts by including children's names and specific contents relevant for each child. Also, children ranked three heroes in order of preference, which were used in the subsequent hierarchical presentation of fear scenarios, to help evoke positive emotions. As homework assignments, children were asked to recall the content of the stories on becoming fearful in darkness situations. Parents were only to prompt the use of imagery scripts during exposure initiated by the child. Children were thus responsible for initiating exposure and were rewarded with points, exchanged from a reward menu, for using the emotive imagery in vivo. The reported results from the study was that the children in the emotive imagery group showed significantly less fearfulness on subjective measures of general fear and anxiety, and parent ratings of darkness fear behavior, and a greater ability to tolerate being alone in a darkness situation, as measured from a darkness tolerance test, in comparison with the wait-list control group. These results were maintained at the three-month follow-up.

One advantage of this study is that a behavioral test was used, to supplement the parent and child reports. Second, the wait-list control group had a waiting period of four months which meant that this extended over the treatment groups three-month follow-up. As the authors themselves discuss it is difficult with this type of design to conclude that it is the emotive imagery in itself that is responsible for the treatment benefit. Also, a possible treatment effect could be the child-initiated exposure to darkness situations occurring between sessions. Additional information as to the phobia status and clinically significant improvement upon treatment termination would be informative and aid study comparisons. 
In summary, emotive imagery has, in several case examples, been described as a useful intervention to treat childhood phobias and fears (see review King et al., 2001), and its effectiveness in reducing fears in children with darkness phobia is tentatively promising (Cornwall et al., 1996). Even so, in the reviews on the criteria of empirically supported treatments, emotive imagery is classified as experimental (see review; Ollendick \& King, 1998). Thus further controlled and single case studies are warranted.

\subsubsection{Graduated in-vivo exposure}

This intervention is a variant of a behavioral treatment known as reinforced practice, dating back to the late 1960s. Theoretically, treatment principles are based on the use of operant procedures, shaping and extinction, used during repeated and controlled graduated exposures, with therapists providing reinforcement and verbal feed-back for overcoming avoidance behavior (Davis \& Ollendick, 2005). Three randomized controlled studies have compared the efficacy of graduated exposure with verbal coping skills (Sheslow, Bondy, \& Nelson, 1983), vicarious exposure (Menzies \& Clarke, 1993) or computer-aided vicarious exposure (Dewis et al., 2001) in children with phobias or assessed as having severe fears.

In the study by Sheslow, Bondy, and Nelson (1983), 32 children in private day-care, aged 4 to 5 years, were recruited via a parental survey report on children's fear of the dark. The children who met a criterion of strong fear of the dark from two repeated behavioral avoidance tests (32 of $74(43 \%))$, were matched for gender and duration of dark tolerance and randomized to one of four conditions: 1. A graduated exposure group, 2. A verbal coping skills group, 3. A combination of both treatments, and 4. A contact-control group. Outcome measures at pre- and post-tests included a behavioral avoidance test, measuring the time the child could tolerate the dark (0-150 seconds), and a child-reported fear rating on a fear thermometer. Two post-tests, differing in instructional demand, were administered to investigate if children's avoidance of the dark could be effectively modified through direct instruction. This was done in a counterbalanced way, where children in the low demand situation were asked to try to stay in the dark as long as they could without feeling afraid, and in the high demand instructions, for the children to try as hard as they could to stay in the dark for as long as possible without feeling afraid.

Children in the exposure group were gradually exposed to nine levels of decreasing illumination, with two exposures at three different and increasing time intervals, of 10, 20 and 30 seconds respectively. In the verbal coping group, treatment consisted of psycho-education about the dark, learning coping phrases, and to practice these phrases during pretend games based on narratives of dark situations. In the combined treatment, children received the verbal coping skills and in the last step exposure (30 seconds for each 
level), instead of pretend games. The duration of the treatment and contact control group time was three sessions of 20 to 30 minutes, on three consecutive schooldays, and for all three treatment conditions, children could signal anxiety verbally or beep a bicycle horn, whereupon the room was fully lit. Children in the contact control group learned to recite a last line of three nursery rhymes, all interventions were reported as carried out in a positive context with songs, play and cookies.

The main finding was that children in the two treatment conditions that included direct exposure to the dark demonstrated significant increases in ability to tolerate the dark. However, no significant differences were found between the low and high demand instruction conditions to differentially modify children's avoidance of the dark. A strength of this study is the experimental design and the use of behavioral test at pre- and postassessment. This is especially important when assessing very young children, for whom correctly labeling their subjective fears might be hard. Unfortunately, following a more strict inclusion criterion, these children were not diagnosed, nor were there any clinical severity ratings done before or after treatment. Also, no follow-up was done, so conclusions about treatment effects over time cannot be drawn, and the sample sizes, eight in each group, is small.

In the study of Menzies and Clarke (1993) 48 children, aged 3 to 8 years, with water phobia were randomized to one of four conditions: 1. In vivo exposure plus vicarious exposure (IVVE); 2. Vicarious exposure (VE); 3. In vivo exposure (IVE); and 4. Assessment only control. All children in treatment had individual weekly sessions for three weeks, and children in the control group were offered treatment after a three-week waiting period. Assessment measurements were a Behavior Rating Scale, consisting of seventeen water-related activities with graded level of difficulty, a sevenpoint scale measuring the children's overall reaction on the water-related activities, and a child and parent report on the Water phobia survey schedule. Assessments were done at pre- and post-treatment, and at a three-month follow-up. Additionally, a generalization assessment was carried out with the treatment groups, one week after the post-assessment, at a different location and swimming pool.

The main findings were that children in the IVVE and the IVE groups showed significant improvement on all four measures, and were significantly more improved from pre- to post-treatment in comparison with the control group. Interestingly, there were no significant differences between the IVVE and the IVE group. Also, children in the VE group had no significant treatment gains over the control group. When testing for generalization effects in an unfamiliar swimming pool, results indicated reductions in scores across all treatment groups. Contrary to the authors' hypothesis, the vicarious exposure treatment not only failed to produce treatment gains on its own but also failed to enhance the gains from the in-vivo exposure 
treatment. At the three-month follow-up, however, the IVVE group showed greater maintenance than the IVE group. This study has several strengths in that a standardized behavioral measure was used, complementing parent and child report, as well as independent observer assessment of the children's overall reactions in the behavioral tests. A weakness, also discussed by the authors, is the short follow-up period, which makes it difficult to evaluate the long-term effects of the treatment.

In 2001, Dewis and colleagues carried out the first single blind, randomized, control trial on the efficacy of computer-aided vicarious exposure (CAVE), in the treatment of children diagnosed with spider phobia. In this study, 28 children and adolescents aged 10-17 years, were randomized to a three 45-minute sessions (every three to four days) of either live graded exposure (LGE), CAVE or a wait-list control group. Screening instruments consisted of the CIDI-A, a computerized questionnaire to aid providing diagnoses, and an estimate of intelligence via either the WISC-III or WAIS-III short form. Self-report instruments (Subjective Units of Distress Scale (SUDS), Spider Phobia Questionnaire for children, Phobia Targets, Adjustment Rating Scales) and Behavioral Approach Test were done at pre- and post-treatment and at a one-month follow-up. The LGE treatment consisted of presentations of increasingly more realistic pictures of spiders, followed by individual live graded exposure tasks, wherein a rating of 20 on the SUDS (range 0-100) was used as a guide to advance to the next exposure level. In the CAVE treatment, a software program instructed the participants to guide on screen a person with spider phobia through increasingly different spider scenarios. Interestingly, the screen figure's anxiety levels were shown via an anxiety thermometer, and as the participants continued the vicarious exposure, the figure's anxiety levels decreased, thus simulating habituation. Common to both treatments, no relaxation, modeling or self-exposure homework instructions were given.

The reported results indicated that the children in the LGE group showed significantly more within-group improvement in symptomatology, on most of the self-report measures, inclusive of the BAT, both from both pre- to post- as well as from pre- to follow-up assessment. Effect sizes measuring the magnitude of treatment change were in the large range for all assessments in the LGE group, both at post-treatment and at follow-up. In contrast, for the CAVE group the effect size was medium to large, in four of the six assessments, at post-treatment, and in five of six assessments at the follow-up. The wait-list group showed small effect sizes on all assessments except for the SUDS, which was large. The authors discussed the weaker results they found for the CAVE in this study in comparison with reported results from studies on adults. Discrepancies might be due to the use of a more compact treatment delivery and a shorter-follow up, wherein children were given less opportunity to try out their new skills; and the CAVE program utilized an adult screen model which might not produce optimal 
learning for children. Also, the omission of homework between sessions and a maintenance program after treatment might also be responsible for the small change reported at the follow-up.

In summary, graduated in-vivo exposure has been classified in reviews as a well-established treatment for treating the behavioral component of the phobia, a general criticism though is the lack of measures on physiology and cognition in the studies (Davis \& Ollendick, 2005).

\subsection{Cognitive-Behavioral treatments}

In this perspective, children's phobias are thought to be maintained through the complex interaction of cognitive and environmental factors, thus both cognitive and behavioral procedures are routinely used in treatment (King et al., 2005). A similar stance is taken by Kendall (1993), where CBT is viewed as using behavioral interventions (e.g., modeling, exposure, operant conditioning, and relaxation), cognitive interventions and psychophysiological methods. Three randomized control studies were found comparing the efficacy of training in the use of verbal control responses (Kanfer, Karoly, \& Newman, 1975), self-control instruction (Graziano \& Mooney, 1980; 1982), and exposure-based contingency management, exposure-based cognitive self-control and education support (Silverman et al., 1999), in children with phobias or assessed as having severe to moderate fears.

In the study by Kanfer, Karoly and Newman (1975), 45 children aged 5-6 years, meeting a behavioral criterion of a strong fear of the dark, were randomly assigned to three experimental groups, differing only in the verbal content used during the training phase, in a well lit room. Thus, in the competence group, children rehearsed sentences emphasizing active control and competence (e.g., "I am a brave girl (boy), I can take care of myself"); in the stimulus group, sentences to reduce the aversive stimulus situation (e.g., "The dark is the best place to go to sleep and have good dreams"); and in the neutral group, story sentences were rehearsed (e.g., "Mary has a little lamb"). Outcome measures were darkness tolerance in seconds and terminal light intensity. Additionally, in a third trial, a generalization test, children were asked to turn down the illumination in the room to the lowest tolerated level.

Overall, children in the competence group developed a greater tolerance of the dark, and a lower illumination level, across the trials and over the stimulus and neutral groups. On the generalization test, though, when children themselves could turn down the illumination, prior training did not result in longer exposure time to the dark; although both the competence and the stimulus groups were able to turn down the illuminationin the room to a 
significantly lower level than the neutral group. The results indicate that previous rehearsal of positive self-instruction on how to cope actively with a stressful situation is more effective than rehearsal of statements concentrating on the positive factors of the dark itself. Interestingly, this verbal training appeared most effective on the specific dark tolerance task in which the children were trained, and generalization effects were seemingly meager.

As in most other randomized control studies, the sample size, with 15 children in each group, was small, rendering low statistical power. Also the children in this study were trained in a laboratory setting, and although pretested for darkness fears, they were not diagnosed as having a fear severe enough to be classified as a specific phobia disorder, and no follow-up was done. Thus, there is little information as to whether the experimental manipulation in a laboratory setting would hold up in a real-life darkness situation, over time, for children with darkness phobias.

Based on the above criticism, Graziano and Mooney (1980) tested whether simple verbal instruction to parents and children on how to carry out home practice of cognitive and behavioral self-control skills could reduce severe nighttime-fears of the dark. The intervention is a combination of selfcontrol and contingency management. In this study, 33 children, aged 6-12 years, with night-time fears of long duration (range 1.5 to 9 years), were randomized to an experimental group of a three-week home training period with three weekly training meetings $(\mathrm{N}=17)$, or to a five-week wait-list control group $(\mathrm{N}=16)$. During the weekly training meetings, children and parents were seen separately. In brief, children learned simple relaxation, to imagine a pleasant scene and to recite "brave" self-statements (e.g., "I am brave. I can take care of myself when I am in the dark."). Children were to practice these exercises every night and keep a record of progress in a booklet. Parents were instructed to supervise, monitor and to reinforce children's efforts with praise and "bravery" tokens. Assessments consisted of parental report using a fear-strength questionnaire, a fear survey and direct observation of children's night-time fear behaviors, at pre- and posttreatment. Also telephone follow-ups were conducted at two months, six months and at one year after the training period.

The main results indicated that children in the experimental group had significantly less night-time fears than children in the control group. These results were reported to be maintained, and continued to increase at the follow-ups; thus, at the twelve month follow-up only one child in the experimental group had not met the behavioral criterion of ten consecutive "fearless" and "perfect" nights. In the treated control group, eleven of the remaining thirteen children had reached the criterion. Interestingly, the authors noted that there were no differences between the experimental and control groups at post-assessment on children's total number of fears, again indicating the specificity effects of the intervention. 
At a 2.5- to three-year follow-up, 31 of the 34 children were reported to have maintained their significant improvement (Graziano \& Mooney, 1982). Two children who initially improved in treatment regressed, albeit not to pre-treatment levels, and continued to have night-time fear problems, and one child made no improvement in treatment and was still fearful at the follow-up. Also, no support was found for the emergence of new problems following treatment, or overall generalization effects to other problem areas. A strength of this study is the long follow-up period, which suggests that the bulk of the training effect is maintained over time. However, one weakness, discussed by the authors, is that the assessments at this follow-up were based solely on self-reports.

In a later study (Silverman et al., 1999), the relative efficacy of two treatment conditions; exposure-based contingency management $(\mathrm{CM})$ and exposure-based cognitive self-control (SC) were evaluated versus an education support (ES) control condition. Eighty-one children, aged 6-16 years, diagnosed as having phobic disorders (simple phobia, social phobia and agoraphobia) according to the ADIS-C/P, were randomized to one of the above conditions. Briefly, all conditions consisted of a 10 -week program in which parents and children were seen separately, with a brief cojoint meeting at the end of the 80-minute session. Both treatment conditions consisted of child exposure in and out of sessions, with the addition of teaching parents behavioral strategies (e.g., positive reinforcement, shaping, extinction and contingency contracting) in the $\mathrm{CM}$ condition, and in the SC condition teaching children self-observation, self-talk, self-evaluation and self-reward, and parents were to support children's reliance on the SC. In the ES condition psychoeducation was given about phobias but no specific information on direct treatment strategy, nor were exposures done in-session or assigned out of session.

The outcome measures consisted of child and/or parent reports of children's anxiety symptoms, fears, negative cognitive errors, depression, behavioral and social problems, and a parent global rating of severity of the child's phobia. Clinically significant improvement was evaluated using three methods: A minimum criterion $\mathrm{T}$ score of less than 70 on the anxious/depressed subscale of the CBCL; not to fulfill the diagnostic criteria at post-test, from the composite scores on the ADIS-C/P; and a substantial reduction of distress on a fear thermometer.

In general the children were reported to show substantial improvement on all of the outcomes measures in both the $\mathrm{CM}$ and SC treatment conditions, and these improvements were maintained at the three-, six- and twelvemonth follow-ups. Unexpectedly, even children in the ES condition were reported to show comparable improvements both at post-assessment and in the subsequent follow-ups.

Some strengths of this study are; the use of a placebo group (ES), a large sample size, the use of treatment credibility assessment (with reported high 
scores for all conditions), the use of a standardized treatment manual, treatment integrity checks, the use of a diagnostic instrument in both the selection and assessment of phobias and comorbid diagnoses, and long-term follow-ups. A weakness of the study is that the outcome measures were based solely on parent-child reports and clinician assessments of diagnostic status. It would have been interesting to see how behavioral tests and the inclusion of physiological measurements might have differentiated the results. Also, the sample size in the post-treatment assessment seemed to have been reduced to a total of 66 , as children with a primary diagnosis other than a specific phobia were excluded, leaving 23 children in the SC group, 30 children in the $\mathrm{CM}$ group and 13 children in the ES group.

\subsection{One-session treatment}

In reviews of child anxiety disorders, one-session treatment (OST) is often classified as a cognitive-behavioral treatment, yet somewhat different due to the one-session format with a maximum of three hours of treatment. In the one-session treatment developed by Öst (1989), the guiding principle is the cognitive-behavioral analysis of the patient's catastrophic cognitions about the phobic situation. This strong belief (e.g., if I take the elevator it's going to stop and I will be trapped in there forever), is seen as maintaining the patients escape and avoidance behavior in that no new information is collected to correct the false belief. The treatment itself combines graduated in-vivo exposure and modeling, wherein the exposure is set up as a series of behavioral tests and the patient is encouraged to draw conclusions from these exposures. The OST has been found to be rapid and effective for adults with various specific phobias (Öst, 1989; 1997), with reported proportions of clinically significant improvement to range between 74 and $95 \%$, and treatment gains have been reported to be maintained at follow-ups, in various studies (Öst, 1989; see review, Öst 1997).

Three treatment outcome studies were found comparing OST with eye movement desensitization reprocessing (EMDR) (Muris, Merckelbach, Van Haafte, \& Mayer, 1997), with EMDR or a computerized exposure group (Muris, Merckelbach, Holdrinet, \& Sijsenaar, 1998), or a one-session treatment with the parent present (Öst et al., 2001) in children diagnosed with specific phobias, according to the DSM-III-R or DSM-IV criteria (APA, 1987; 1994).

In the study by Muris et al. (1997), 22 children, aged 9-14 years, with spider phobia were treated with one session of exposure in vivo, and one session of EMDR (1.5 hours each), in a cross-over design, with all children receiving both treatments. In the OST, children confronted real-life spiders in a hierarchical structured way, with the therapist as a model. In the EMDR treatment, three aversive experiences with the phobic object were desensitized (e.g., the most aversive, the most recent and future 
confrontation). In brief, techniques included helping the child formulate positive and negative cognitions of the aversive event, to imagine negative experiences and accompanying negative cognition, upon which lateral eye movements were initiated and repeated until a neutral content of the image was reported. Treatment outcome was measured with child self-report of spider fears, behavioral avoidance test of spiders and skin conductance level (SCL), at pre-treatment and after treatment one and two. The two treatments were found to be equally effective on self-report measures of spider fear, however, OST was found to be superior in reducing children's avoidance behaviors and on the state of anxiety rated during the BAT. No treatment outcome differences were found on the physiological measure (SCL). The authors conclude from this study that EMDR has no additive value to OST in the treatment of this type of animal phobia.

A strength of this study is that the children had been diagnosed with a diagnostic instrument (albeit only with a parental interview), and the outcome measures were in multiple domains, i.e. subjective, behavior and physiology. There are, however, also several limitations, some of which the authors discuss in the paper: carry-over effects with this type of design where no control group was included, also the use of two different therapists for the treatments, wherein one had long treatment experience and specific training (EMDR), and for the OST, minimal training and no experience of treating children. Thus, OST might have been even more efficacious with an equally trained therapist. Another limitation is the lack of reported diagnostic severity from pre- to post-treatment, there were no reports on clinical significant improvement and no follow-up data.

A year later a second study was published by the same research group (Muris et al., 1998). This time the efficacy of EMDR versus exposure was tested in a between-subjects RCT design, in children (girls) aged 8-17, diagnosed with spider phobia according to the DSM-III-R criteria (APA, 1987). In the first phase, the children were randomized to a 2.5-hour treatment of EMDR, exposure in-vivo or a computerized exposure group (a placebo treatment). In the second phase, all children were treated with a 1.5hour session of exposure in-vivo. The two active treatments, EMDR and exposure in-vivo, were based on the same treatment principles described above in the first study from 1997. In the computerized exposure, children were confronted with spiders, in a hierarchical manner, differing in size, movement and reality, on a computer screen. Outcome measures were the same as used in the previous study, with the omission of the physiological measure, and were obtained before and after the first and second treatment phases.

Overall, from the first phase of treatment, the 2.5-hour exposure in-vivo treatment showed significant improvement on all outcome measures, whereas this was only the case for EMDR on a self-report measure of spider fear, and the computerized exposure showed a non-significant improvement. 
From the data analyses in phase two, authors report that no evidence was found that EMDR treatment potentiated the efficacy of the subsequent exposure in-vivo treatment. Thus, the authors conclude that exposure in-vivo is the treatment of choice for children with spider phobia.

This second study, being a randomized controlled treatment, has advantages over the previously used crossover design. Moreover, a placebo control group was used, which strengthens the conclusions that can be drawn. Also in this study the authors interviewed parents and children separately for child diagnosis, which is being increasingly asked for in clinical trials. Interestingly, children were asked to rate the effectiveness of the three treatments, and exposure in-vivo was stated as being more effective in reducing spider fears over the other two treatments. On the limitation side, with the exclusion criteria of comorbid psychopathology, and a sample of only girls, it is hard to predict how the results might generalize to children with comorbidity, and to boys. Also, there were no reports of clinical significant improvements, nor how many children were diagnosis-free after treatment, and no follow-up, so one does not know if treatment gains are maintained over time.

More recently, two forms of the one-session exposure treatment (OST) were evaluated in a larger RCT with a sample of 60 children aged 7-17 years, who fulfilled the diagnosis for various specific phobias on the diagnostic screening interview ADIS-C/P, according to the DSM-IV criteria (APA, 1994) (Öst et al., 2001). The children were randomized to three conditions: (i) one-session exposure treatment alone, (ii) one-session exposure treatment with the parent present, or (iii) a wait-list control group for a period of four weeks. The latter group was re-randomized after the waiting period to one of the active treatments, resulting in a final sample of 30 children in each treatment. In brief, the treatments were described as being adjusted to the developmental level of the children, with the addition that in the parental condition, parent's behavior could range from being an observer to an active and supportive model.

Outcome measures consisted of child and parent interviews on the mini versions of the ADIS-C/P (i.e., the sections containing the diagnoses children had fulfilled), graduated behavioral approach tests (BAT) for each phobia, measures of physiological reactions (blood pressure, heart rate), at baseline and at highest step accomplished in the BAT, with accompanying anxiety rating, and several self-report scales tapping into phobic fears, general anxiety, anxiety sensitivity and depression. Assessments were done at pre-treatment, post-treatment and at a one-year follow-up.

The main results showed that the two treatments were significantly more effective than no treatment, on independent assessor rating of phobic severity, the BAT and accompanying anxiety scores. No significant differences were reported on the physiological measures, or the self-report measures between the groups. The two active treatments were overall 
equally effective and differed only on the BAT scores at post-treatment. The measure of clinically significant improvement showed that the two treatment groups had significantly more clinically improved children (child alone ranges $63-93 \%$; parent present ranges $70-77 \%$ ) than the wait-list controls $(0-16 \%)$.

Several interesting findings were also reported from this study. First, that comorbidity at pre-treatment was not associated with poorer clinical improvement, second, that a higher proportion of girls improved, and third, children with animal phobias improved more clinically than those suffering from other miscellaneous phobias.

Some limitations of this study, most of which are discussed by the authors, are; the exclusion of eight non-motivated children due to ethical reasons, floor effects on self-report measures where many children were in the normative ranges at pre-treatment, no treatment integrity checks were done nor therapist competence ratings. More seriously, a complete diagnostic interview was not done at the one-year follow-up, which is a limitation as one purpose of the study was to investigate whether the treatment also had effect on comorbid disorders. The strengths include the design itself, with two treatments and a control group, a one-year follow-up, the use of psychometrically sound diagnostic instruments, with high interrater agreements on primary and secondary diagnoses, the multi-assessment approach and reports of clinically improved patients.

In summary, from the above overview of RCTs with cognitive-behavioral treatment in youth with specific phobias (and anxiety) disorders, it seems that CBT is more effective than control group conditions. However, versus an active placebo it is too early to draw any firm conclusions. Support for this is provided in a recent meta-analysis over 24 studies by In-Albon and Schneider (2007), wherein the overall mean effect of cognitive-behavioral treatment, pre- to post-treatment, was reported to be large $(d=0.86)$, but small $(d=0.13)$ in the wait-list control conditions and interestingly, a moderate overall effect $(d=0.58)$ was reported for the attention placebo control condition. Thus, CBT to date is "only" rated as probably efficacious in reviews addressing empirically supported treatments for specific phobias in children (Davis \& Ollendick, 2005). In contrast, a comparison between a one-session treatment versus active interventions, active placebo and control group conditions, in the treatment of specific phobias in youth, has to date yielded the advantage to OST. This conclusion was likewise drawn by Davis and Ollendick (2005), who also suggested that OST be ranked as a wellestablished treatment. 


\subsection{Cross-country comparison}

Although the above described randomized treatment outcome studies have been conducted in various different countries (see Table 3), with results at least better than a no-treatment or a wait-list control group, no study to date in an RCT design has examined the efficacy of a cognitive-behavioral treatment, or more specifically OST, across two countries and cultures, in children and adolescents diagnosed with a specific phobia. Such a study is important in that it might yield some information as to the portability and generalizability of the treatment intervention to other samples, sites and across a range of therapists with varying educational background.

\subsection{Conclusions of randomized treatment studies}

From the literature overview on randomized treatment outcome studies on children with phobias, it seems that doing something is better than doing nothing, and that conducting in-vivo exposures, especially a one-session treatment, is most promising. However, the OST only enjoys a wellestablished status across one component (behavioral) and is deemed probably efficacious in another component (subjective fear), leaving two important components (cognitive and physiological) in need of further inquiry. Also, importantly, too few studies have included a variety of specific phobias, across a wide age range in children also diagnosed with comorbid disorders. In addition, no study has to date made a cross-country comparison. In order to gain more knowledge and be able to draw more firm conclusions on what works for whom, it is important that future research studies carefully specify the sample characteristics, through psychometrically sound diagnostic instruments and assessments, use a multiassessment approach tapping into the domains of behavior, cognition, emotion and physiology, increase sample sizes in the design for adequate statistical power to detect differences, increase the use of manuals, and use treatment integrity checks and systematic follow-ups, in large randomized controlled designs, preferably moving on from wait-list control groups to more active placebo-control conditions and competing treatments. Such work is much needed as at present many children and adolescents are not reaching remission rates, as they still meet the criteria of their principal anxiety disorders. 


\section{Aims of the study}

The purpose of this dessertation has been to contribute to our understanding of fears, anxieties and the treatment of specific phobias in children and adolescents as they present in clinical research settings in two countries. In this work, parental rearing behaviors were examined to see if these were related to general anxiety symptoms or secondary anxiety disorders. Further, phobic and anxiety disorders in the children were assessed through diagnostic screening instruments, and parent-child agreement on these were examined; and in closing, the efficacy of a one-session treatment for children and adolescents suffering from a variety of specific phobias was evaluated. 


\section{Overview of empirical studies}

The present dissertation consists of three studies on children and adolescents presenting with various specific phobias in Sweden and the USA (Study I and III). The overall aim was to contribute to the understanding of childhood fears, anxieties and phobias and to evaluate the efficacy and portability of a one-session treatment of specific phobias in youth, in two countries. In study I, specific parenting behaviors were examined to see if these might have an influence on childhood anxiety, in Sweden and Virginia. In study II (Sweden), parent-child agreement was explored on a commonly used diagnostic screening instrument for youths, and more specifically if child factors (motivation or self-concept) and parent factors (general psychopathology or diagnoses) differentially influenced this agreement. Study III was the randomized clinical treatment trial in Sweden and Virginia.

Children were recruited, based on symptoms of phobia, through referrals from child psychiatric services, school health services, family medical practices, and in response to newspaper advertisements in Stockholm County, Sweden, and areas of southwestern Virginia in the United States for an ongoing treatment project for specific phobias. Study I and study II were conducted on pre-treatment measures.

\subsection{Study I: Parenting and childhood anxiety: A clinical study in Sweden and Virginia}

\subsubsection{Aims}

There has been some controversy as to the number of dimensions that underlie the Parental Bonding Instrument. The first objective of this first study was to test the dimensionality of the instrument. Based on the result of Uji et al. (2006), it was hypothesized that the four dimensions (care, indifference, overprotection and encouragement of autonomy) underlie the PBI, and this was tested for different generations and across countries. The second objective was to examine the association between perceived parenting behaviors and clinical symptoms in children. It was hypothesized 
that the parental behaviors of indifference and/or overprotection, in comparison with care and encouragement of autonomy, would be more strongly related to anxiety symptoms and co-occurring disorders in the children and that the patterns would be fairly similar between Sweden and Virginia.

\subsubsection{Method}

In this study, a subset of the original sample of children and their parents participated, those for which there was enough complete data to analyze perceived parenting behaviors across three generations $(\mathrm{N}=81$ (Sweden) and $\mathrm{N}=69$ (Virginia)). The children were between 7 and 15 years of age (M $=10.93(\mathrm{SD} 1.90)$ in Sweden; $\mathrm{M}=9.39$ (SD 1.93) in Virginia). As to gender, $50(61.73 \%)$ children in the Swedish sample and $27(39.13 \%)$ in the Virginian sample were girls. All children presented with a specific phobia according to the DSM-IV (APA, 1994).

Child factors (anxiety symptoms and co-occurring diagnoses) were examined. Co-occurring secondary diagnoses were assessed with the ADISC/P (Silverman \& Albano, 1996) and general anxiety symptoms with a selfreport inventory, the Multidimensional Anxiety Scale for Children (MASC; March et al. 1997). Children and parents also completed the Parental Bonding Instrument (Parker et al., 1979). Data for the PBI was obtained from parents' perceptions of their own parents behavior (G1) using retrospective report ("How did your mother/father parent you?"), whereas data of parents' parenting behavior (G2) and children's perceptions of this behavior (G3) were obtained on current perceptions ("How are you parenting your child?") and ("My mom/dad likes me to make my own decisions..."), respectively. An initial exploratory factor analysis on the PBI items indicated that two of the 25 items (items 8 and 10) exhibited weak factor loadings for most generations in both countries, and these were excluded from further analysis. The remaining items were generally within acceptable standards. The hypothesized four-factor representation of the PBI was tested using confirmatory factor analysis and the maximum likelihood procedure (Lisrel 8; Jöreskog \& Sörbom, 1996) was used to contrast the four-factor model, with a three-factor model (Cox et al., 2000), the original two-factor (Parker et al., 1979), as well as a uni-factor model and a structural null model.

\subsubsection{Results and discussion}

In line with the hypothesis, a confirmatory factor analysis showed that the four-factor representation of parental behavior provided an adequate fit for all three generations, and measurement models were quite similar across countries. This suggests that the Parental Bonding Instrument may be used to 
measure parental bonding in almost the same way for different generations and in different clinical research settings.

The second question concerned the association between "poor" parenting behaviors (indifference and overprotection) and clinical symptoms in the children. The main finding in the Virginian sample was in line with the hypothesis, wherein perceived overprotection in parents and the children's perceptions of their mothers and fathers as overprotective were associated with significantly higher general anxiety symptoms in children. This was likewise so for perceived parental overprotection and number of comorbid diagnosis in the children. The only significant differences between the two clinical samples were for perceived parental self-report of overprotection and children's ratings of their mothers as overprotective, and associated anxiety symptoms in the children. In contrast for the Swedish sample, but also in line with the hypothesis of "poor" parenting" children who perceived their mothers as being indifferent had significantly more general anxiety symptoms and were more comorbid, however, a Fisher's $\mathrm{Z}$ test for difference in magnitude between the samples showed that this result was not significant.

Important and interesting is that several other researchers have also found support for the association between children's perceptions of specific "poor" parenting behaviors and anxiety disorders or child anxiety (Bögels \& Brechman-Toussaint, 2006; Rapee, 1997; Siqueland, Kendall, \& Steinberg, 1996). Children are increasingly being seen as active agents in the parentchild parenting process (Bornstein, 2002), capable of eliciting both optimal and less optimal parenting. In this complex feed-back system both parental anxiety and temperamental characteristics in the parent and child are likely to be intricately interwoven to produce differential outcomes in anxiety symptoms in children.

\subsection{Study II: Exploring child and parent factors in the diagnostic agreement on the Anxiety Disorders Interview Schedule}

\subsubsection{Aims}

The main objective of this study was to explore why parent and child agreement on child psychiatric diagnosis is generally poor. To this end three areas were analyzed. First, overall parent-child agreement on the diagnostic categories and severity ratings, in principal and secondary child diagnoses. Second, specific child factors such as age, gender, motivation and self- 
concept, and third, specific parent factors such as general psychopathology and presence of diagnoses were examined.

Predictions, based on earlier research, were that children who were not motivated to undergo treatment for their specific anxieties or fears, and children with a low self-concept, would be more likely to disagree with their parents. Further, that lower parental psychopathology and diagnoses would be related to stronger parent-child agreement on children's diagnoses and severity ratings.

\subsubsection{Method}

The participants were 110 children with a specific phobia (SPP) diagnosis according to the DSM-IV (APA, 1994) which was their principal anxiety disorder, based on diagnostic interviews with the Anxiety Disorders Interview Schedule, parent and child versions (ADIS-C/P; Silverman \& Albano, 1996) and clinical consensus. The children were between 8 and 14 years of age $(\mathrm{M}=11.11 ; \mathrm{SD}=1.88), 71$ were girls $(64.5 \%)$ and 39 boys. One or more secondary diagnoses were found in 54 (49.1\%) of the children. The most common secondary diagnoses were another SPP (58.9\%), followed by separation anxiety disorder (SAD:23.2\%), generalized anxiety disorder (GAD:19.6\%), social phobia (SOCP:16.1\%), attention deficit hyperactivity, all subtypes (ADHD:8.9\%); depression (DEP:1.7\%), agoraphobia (AGP:1.7\%) and obsessive-compulsion (OCD:1.7\%). As for parents $(\mathrm{N}=$ 99), 36.4\% had one or more diagnoses (SPP:24.2\%; SOCP:12.1\%; GAD: $8.1 \%$; panic with agoraphobia: $4 \%$; DEP:4\% and dysthymia:2\%).

The measures used consisted of semi-structured diagnostic interviews with the ADIS-C/P, with parents and children interviewed separately by different clinical psychologists, to assess for major childhood psychiatric disorders and to obtain separate ratings from parents and children. Ratings on this instrument range from 0 to 8 , and a cut-off score of 4 , a moderate degree of impairment, is used as an indication of a diagnosis. A score of 8 indicates that a child is presenting with extremely serious symptoms and a very limited quality of life. Parents were interviewed with an equivalent semi-structured diagnostic interview ADIS-IV (Brown et al., 1994) to screen for various diagnoses and assessment of symptoms, avoidance and ratings of interference in daily life. Also, the Global Severity Index from the Symptom Check List-90-R (SCL-90-R) was used to measure parents' (N=107) general psychopathology. Child self-report inventories consisted of Nijmegen Motivation List 2 (NML2; Keijsers et al., 1999), to assess motivation for treatment and a Self-Concept Scale (SCS; Beck et al., 2001), to assess how children view themselves. All of these measures were part of a larger assessment battery prior to entering the randomized clinical trial. 


\subsubsection{Results and discussion}

Not unexpectedly, perhaps, parent-child agreement on the principal specific phobia diagnosis was excellent (97.3\%) in this study from a specialist phobia clinic. It is interesting, though, that the agreement was not only high on the phobia and moderately so for its severity ratings, but that this problem was termed as the most important for the child to be helped with, from both the parent and child perspectives. This is in contrast with the findings of Yeh and Weisz (2001) from community mental health clinics, where poor parentchild agreement was found on referral problems, even when these were grouped in broader problem areas.

In the present study, fair levels of concordance between parents and children were also found on most co-occurring secondary diagnoses and fair to good on the diagnostic severity ratings. Only for one anxiety diagnosis, social anxiety, did we find the poor levels of agreement reported by other researchers (Grills \& Ollendick, 2003; Rapee et al., 1994).

On examining specific child factors, older children were found to agree significantly more with their parents on the severity of SAD only, and girls had more acceptable levels overall of parent-child agreement on diagnoses than boys (for SAD $p<.0001$ ). There are previous reports that parent-child agreement is not generally age dependent (Jensen et al., 1999), and a stronger parent-daughter agreement, compared with parent-son agreement, has previously been reported by Safford et al. (2005). In line with expectations, children's high motivation was positively associated with parental agreement on both diagnoses and severity ratings (for ADHD $p$ $<.001$; a third SPP $p<.004$ ). In contrast to our predictions, a reported low self-concept was associated with overall stronger parent-child agreement on diagnoses (a third SPP $p<$.0001) and severity ratings (a third SPP $p<$. 0001; SAD $p<.0001$; GAD $p<.024$ ). One of several explanations may account for this unexpected result. First, that with the children primarily coming into a clinic for assessment and pending treatment of a specific phobia, it might not seem so stigmatizing, thus making it easier for the children also to disclose information on other problem areas, where a low self-concept was not a hindering factor. Second, an alternative plausible explanation is that the measures used to assess for self-concept may have tapped into constructs related to self-concept other than self-representation and self-esteem.

As to parent factors, also in contrast to our predictions, a high parental general psychopathology was marginally, and parental diagnosis was overall, associated with a stronger parent-child agreement on child diagnoses (for ADHD $p<.0001$ ) and severity ratings (a second SPP $p<$. 001; SAD $p$ $<.001$; ADHD $p<.0001$ ). The results on parental psychopathology are partly in contrast to earlier work, but more recent reviews have reported inconsistent patterns (De Los Reyes \& Kazdin, 2005; Grills \& Ollendick, 
2002). The findings for parental diagnosis and overall significant patterns of higher parent-child agreement on child diagnoses and severity ratings are new, however. Several possible explanations could account for them. First, it might be that parents with diagnoses are more tuned in to their child's fears, worries, anxieties and avoidance behavior, and are thus better able to report on them. Second, children of these parents have learned to recognize parental anxiety and are more able also to recognize it more readily in themselves. Third, it might also be that parents with anxiety disorders "see" disorders in their children and the children come to agree with their parents over time. Fourth, although some parents in the project had a diagnosis themselves, they were overall functioning well and so it might be that the level of psychopathology is something to consider also. These suggestions would be interesting to test in future studies.

\subsection{Study III: One-session treatment of specific phobias in youth: A randomized clinical trial in the USA and Sweden.}

\subsubsection{Aims}

The primary objective of the third study was to compare a one-session treatment with a credible education support therapy condition and a wait-list control condition for children and adolescents presenting with various types of specific phobias. A secondary objective was to determine whether treatment effects would be comparable in a Swedish and USA clinic.

The predictions were that the one-session treatment would be superior to the education support therapy condition, both at post-treatment and at the six-month follow-up, and that both active interventions would be superior to the wait-list control condition at post-treatment.

\subsubsection{Method}

Out of the 226 participants who were screened and who completed the diagnostic interviews (ADIS-C/P), 196 children with a specific phobia according to the DSM-IV (APA, 1994) participated (101 from Stockholm, Sweden, and 95 from Virginia, USA). The children were between 7 and 16 years of age, mean ages 11.1 $(\mathrm{SD}=1.9)$ in Stockholm, and 10.9 years $(\mathrm{SD}=$ $1.7)$ in Virginia. In Stockholm, 63 were girls (62\%) and 38 boys, and in Virginia, 43 were girls (45\%) and 52 boys, respectively. Of the Swedish sample, $70 \%$ had an animal phobia, compared with $53 \%$ of the Virginian sample $($ Sweden $=\operatorname{dogs} 29$; spiders, 15; wasps, 9; birds 5; snakes 4; ants 4; 
insects 4 and snails 1: Virginia $=\operatorname{dogs} 17$; spiders; bees, 7; other insects 7; and worms 1). A variety of other types of phobias were found in the Swedish $(30 \%)$ and in the Virginia sample (47\%) (Sweden = enclosed spaces 13 ; loud noises 6; thunderstorms 6; costumed characters 2; flying 1; water 1; mushrooms 1 and rain 1), (Virginia = dark 11; thunderstorms 9; loud noises 3 ; costumed characters 6; flying 3; water 3; and taxidermy-prepared animals 2 ). Forty-four (44\%) of the Swedish and $84 \%$ of the Virginian participants were comorbid with at least one additional disorder (e.g. SPP, SAD, GAD, SOCP, major depression, ADHD, OCD and enuresis).

Within clinic, participants were randomly assigned to a one-session exposure treatment (OST), education supportive therapy (EST) or to a waitlist control group (WLC). The WLC were, after the waiting period (approx. 5 weeks), re-randomized to one of the two active treatments. The treatments were conducted by four therapists in Stockholm and six in Virginia, all treating approximately the same number of participants in each condition.

The assessment battery before treatment, after treatment, and at a sixmonth follow-up, consisted of an independent assessor rating, blind to treatment assignment, of the severity of the phobia and comorbid disorders by separate parent and child interviews, respectively (ADIS-C/P). Self-report and parent-report inventories were completed and standardized behavioral approach tests (BAT) were conducted, adapted for each phobia type. Measured variables were; disorder severity, phobic anxiety and approach behavior, fears and general anxiety, quality of life, motivation for treatment, self-concept and parent's ratings of children's internalizing and externalizing problems. Treatment credibility on the assigned treatment was assessed by children and parents respectively, and therapist adherence and competence was rated by independent assessors.

\subsubsection{Results and discussion}

All participants completed the treatment and the post-treatment assessment. At the time of the six-month assessment, nine children assigned to OST and eight children assigned to EST were not available for a follow-up. The main findings were that both treatment conditions evidenced superior outcomes to the WLC condition on the independent assessor ratings of phobic severity and on the percentage of participants who were diagnosis-free following treatment $(\mathrm{OST}=55 \%$; EST $=23 \%$ and $\mathrm{WLC}=2 \%)$. However, the three conditions did not significantly differ on the behavioral approach test, selfreport, or parent-report measures at post-treatment. In comparison, the analyses between the OST and EST following treatment revealed that OST was superior to EST, with lower clinician ratings of phobia severity, a higher percentage of participants who were diagnosis-free, lower child ratings of anxiety during the BAT and higher treatment satisfaction reported by both children and parents. Also participants in the OST had a greater proportion 
of clinically significant improvement (CSI) versus the EST (33\% vs. 12\%) at post-treatment.

At the six-month follow-up comparison between OST and EST showed that participants in the OST condition continued to do better, with lower clinician ratings on phobia severity and a higher percentage were diagnosisfree $(\mathrm{OST}=49 \%$; EST $=35 \%)$.

The prediction that both active treatments would be superior to WLC was corroborated, whereas the prediction that a one-session treatment would be superior to the education support therapy condition, both at post-treatment and at the six-month follow-up was only partially supported. Although the recovery rates are similar to those reported for the treatment of phobic disorders with contingency management and exposure in combination (Silverman et al., 1999), they are lower than those reported by Öst et al. (2001) using OST for a various specific phobias (82\% CSI at post-treatment and $80 \%$ at one-year follow-up).

Overall the treatment outcomes were similar between Sweden and Virginia. For example, the percentage of participants who were diagnosisfree in the OST condition at post-treatment was $48 \%$ in Sweden and $56 \%$ in Virginia; and at the six-month follow-up, $44 \%$ versus $54 \%$ respectively. Interestingly, out of all sociodemographic variables entered in the analyses, only gender predicted treatment outcome, and this was only at the six-month follow-up where significantly more girls than boys responded to OST. This advantage for girls was similarly reported by Öst et al. (2001). 


\section{General discussion}

The aim of the following section is to highlight, elaborate and discuss the contribution of the present dissertation to the understanding of childhood fears, anxieties, phobias and the treatment of specific phobias, specifically from two-country clinical research settings. Also methodological issues, limitations, clinical implications, and directions for future research are addressed.

\subsection{Parenting and childhood anxiety in a clinical sample in Sweden and Virginia}

The purpose of this study was twofold. First, it was to make a contribution to the ongoing debate about the number of dimensions that underlie the Parental Bonding Instrument. Based on the work by Uji et al. (2006), it was hypothesized that four dimensions underlie the PBI (care, indifference, overprotection and encouragement of autonomy), and this was tested for different generations and across two countries. Second, it was to test the hypothesis that the parental behaviors of indifference and/or overprotection would be more strongly related to anxiety symptoms and co-occurring disorders in the children, with fairly similar patterns in the two clinical samples.

Participants were a subset of the original sample of children, with a specific phobia according to the DSM-IV (APA, 1994), and their parents. Briefly, the results supported the hypothesis that four dimensions underlie the PBI, and the four-factor model provided the best fit overall for the generations in both countries. Also, for the Virginian sample and to some extent the Swedish, the finding that "poor" parenting (indifference and overprotection) is associated with more anxiety symptoms and comorbid diagnosis was in line with the hypothesis.

What conclusions can be drawn from the results of this study? First, on a methodological note, it is suggested that the PBI may be used to measure perceived parenting in almost the same way for different generations and in different, albeit Western countries. Second, that parenting as perceived by parents and children, seems overall to be more similar than different across 
Japan, Sweden and the US, despite the fact that these countries have different cultures. This finding of some cross-cultural consistency is important and adds some confidence to our ability to generalize results. Third, the results lend partial support to the role of "poor" parental behaviors and especially that overprotection seems to be a parenting behavior that is non-optimal for children and adolescents with an anxiety disorder. However, there are also some differences between the two clincial research settings, as "poor" parenting had slightly different influences in Sweden and Virginia. In the Virginia sample, overprotection was more often associated with child anxiety, whereas in the Swedish sample this could also be an indifferent parenting, or low care.

The results from the present study lend some support to current models of anxiety, wherein parental over-control seems to communicate to the child the presence of a constant threat, resulting in hyper-vigilance and fear, and where the child is given less opportunity to approach situations on their own, making it difficult for new learning to take place (Barlow, 2002; Chorpita et al., 1998; Dadds, 2002 \& Rapee, 1997). However, it is also important to acknowledge that parenting seems to be a complex and dynamic process where children are actively involved, from the very beginning, in also shaping the parenting they receive. In this parent-child interaction, early temperament characteristics in the child (e.g., behavioral inhibition) and anxiety in the parent are likely to inter-play, making the research field complex but at the same time also intriguing.

\subsection{Parent-child agreement on anxiety disorders}

The aim of this study was to examine parent-child agreement on diagnoses and severity ratings on principal and secondary child diagnoses in a commonly used diagnostic screening instrument (ADIS-C/P; Silverman \& Albano, 1996). Also child factors (age, gender, motivation, and self-concept) and parent factors (general psychopathology and diagnoses) were explored to see if these differentially influenced parent-child agreement on child diagnoses and severity ratings. The participants were 110 children from Sweden, between 8 and 14 years of age, with a specific phobia diagnosis. Briefly, the main findings were that parent-child agreement on the principal specific phobia diagnosis was very high, and moderately high for phobia severity. Also, fair levels of agreement were found on most co-occurring secondary diagnoses and severity ratings. As predicted, children scoring high on motivation, were found to have an overall stronger parent-child agreement on child diagnoses and severity ratings than children with a low motivation. The opposite was true for children with reported high selfconcept. Also in contrast with the prediction, parental general 
psychopathology and especially parental diagnosis was related to a stronger concordance on child diagnoses.

What tentative conclusions can be drawn from this? First, that the high concordance found between parents and children on the principal specific phobia diagnosis is not so surprising, as this is what the families sought help for. However, it remains interesting that the agreement was as high as it was, with both parties also reporting that this was the principal problem the child needed help for, considering the low agreement reported elsewhere for children entering treatment for phobic and anxiety disorders (Safford et al., 2005). Another explanation for the high agreement might also be that few clinics are as specialised on phobias as the two in the study. Second, although common sense psychology would lead us to suspect that children scoring high on self-reports on motivation (for treatment and the work entailed around this) would have a higher rate of parent-child agreement on child diagnoses than children with low scores, the data from the current study also lends support for this. Third, self-concept as measured in the present study turned out to be an interesting factor with unexpected results. Why is the parent-child agreement on child diagnoses poorer for children scoring high on self-concept? One suggestion might be that the children scoring high on the SCS were at the extreme end of the scale, however, children in the high self-concept group had a mean score of 63.09 (4.84), which is similar to the mean score average of 62.80 (7.80) presented in the study by Ghaderi, Mårtensson and Schwan (2005) among fifth-grade school children. An alternative suggestion is that the measure used to assess selfconcept may have tapped into constructs related to self-concept other than self-representation and self-esteem. One closely related construct that comes to mind is social desirability and social evaluation. Several researchers have suggested that children may be underreporting anxiety problems due to concerns with social evaluation (Safford et al., 2005), wanting to present themselves in a favorable way (Di Bartolo et al., 1998). That children in the present study reported overall fewer diagnoses than their mothers did is similar to that reported by Safford and colleagues (2005) for children presenting with generalized anxiety disorders, separation anxiety disorder and social phobia.

The above result is important as to date there is no "gold standard" as to which report, parent or the child, is the most reliable. Child factors then, which might suggest a priori when this agreement is more likely to be good or very poor, might aid the clinician in deciding when to include both parents and children in the diagnostic interview and to add more time to the assessment procedure.

As for parent factors, such as general psychopathology, the parent-child agreement was only marginally and positively related to a stronger parentchild agreement. This is overall in line with more recent reviews, with reports of inconsistent patterns or overall weak support (Grills \& Ollendick, 
2002; De Los Reyes \& Kazdin, 2005). However, the finding that parents with at least one diagnosis themselves have an overall higher agreement with their children on child diagnoses and severity ratings is new and intriguing. It could be the case that, as these parents fulfilled the criteria for a diagnosis within the assessment procedure, these parents might not have a serious psychopathology. In fact, they might even have been more inclined to admit problems themselves in this particular context as a way of identifying with their child and/or because they had particular faith in the experts within the research clinic. Thus, it will be interesting to see if these findings can be replicated in future studies. It would also be interesting to examine if children of these parents also have better treatment outcomes. That is, is the higher parent-child agreement found on child diagnosis for parents with a diagnosis themselves, also related to less anxiety problems in the child at post-treatment and at follow-up, in comparison with parents without diagnosis?

\subsection{Cognitive-Behavioral treatment of specific phobia in Sweden and Virginia}

The main purpose of this study was to compare a one-session treatment with an education supportive therapy condition and a wait-list control condition for children and adolescents presenting with various types of specific phobias, in two clinical research settings, in Sweden and Virginia. It was predicted that the one-session treatment would be more effective than education supportive therapy, both at post treatment and at the six-month follow-up, and that both the active interventions would be superior to the wait-list control condition. Participants were 196 children, 101 from Stockholm, Sweden, and 95 from Virginia, USA, between 7 and 16 years of age, with a specific phobia according to the DSM-IV (APA, 1994).

In brief, it was found that both OST and EST were superior to the WLC with regard to the independent assessor (blind to treatment randomization) ratings of phobic severity and number of diagnosis-free participants at posttreatment, but not significantly so on any other measures. In a comparison between the active treatments, children who had received OST were to a greater extent free of their specific phobia diagnoses, rated less anxiety during the behavioral approach test, were more satisfied with the treatment and had more clinical significant improvement. At the six-month assessment, children in the OST condition continued to do better with lower clinician ratings on phobia severity and a higher percentage were diagnosis-free. As predicted, both interventions were superior to the WLC, however, there was only partial support for OST being superior to EST at post-treatment and at the six-month follow-up. 
The reported non-significant differences between OST and EST on selfreport and parent-report measures is not inconsistent with previous findings. For example, in the study by Öst and colleagues (2001) on specific phobias in youth, there were no significant differences between OST and WLC conditions, on children's self-report of fear, anxiety or depression. In line with this, in the clinical trial conducted by Silverman et al. (1999) on youth with phobic disorders (simple phobia, social phobia and agoraphobia), nonsignificant findings were reported between exposure-based treatment and EST on child-reported fear, anxiety and depression, and also on the CBCL scores, as reported by the parents. In a recent review, similarly, attention placebo control conditions were reported to have a moderate overall effect $(d=0.58)$ from pre- to post-treatment (Davis \& Ollendick, 2005).

One "problem" with samples of children with specific phobia disorders is that many of the children score in the normative ranges on both self-report and parent-report of general anxiety and depression (albeit still fulfilling the diagnostic criteria of a specific phobia). If there are floor effects already at pre-treatment, then it is basically impossible to obtain any significant positive effects at post-treatment. A similar problem can be found on BAT measures. Although the BAT was standardized to accommodate for each specific fear, in reality certain natural environmental fears (e.g., storms and lightning) had to be artificially created, meaning that many children could reach a high step already at pre-treatment. Also, the various specific phobias could not be measured on an instrument specifically tapping into each single phobia as there are no such self-report measures available. Thus, many of the instruments are measuring general anxiety and fears.

Although the recovery rates in the present study, in Sweden and Virginia, are similar to those reported for the treatment of phobic disorders with exposure-based contingency management and exposure-based cognitive selfcontrol (Silverman et al., 1999), they are lower than those reported by Öst et al. (2001) using OST for a various specific phobias, in a Swedish sample of young people ( $82 \%$ CSI at post-treatment and $80 \%$ at one-year follow-up). One explanation for this difference could be the use of more experienced therapists in the previous study (Öst et al., 2001). In the study of Öst et al. (2001), the therapists were licensed psychotherapistst with eleven and six years respectively of post-CBT training, and with extensive training in treating children with specific phobias. There is some support from the review by Stein and Lambert (1995) on graduate training in psychotherapy, that favors more trained therapists, as modest effect sizes were reported on a variety of outcomes. Importantly, it was found that in many outpatients settings therapists with more training had fewer therapy dropouts than less trained therapists (Stein \& Lambert, 1995). More training then could account for some of the differences found between the study by Öst et al. (2001) and the present study. 
Overall, the similarity between outcomes in Sweden and Virginia was striking, suggesting that the OST is portable, at least between Western countries. No sociodemographic variables predicted outcome post-treatment in either country. However, girls were found to respond to OST more strongly than boys at the six-month follow-up. This has similarly been reported in the previous study by Öst and colleagues (2001), but others using contingency-based exposure treatment have not obtained this result (Silverman et al., 1999).

\subsection{Methodological comments and limitations}

There are several limitations that need to be addressed, although some have already been mentioned in the discussion above. First and foremost, the participants in the studies are clinically defined samples, who have themselves contacted specialist research clinics. Thus, generalizations beyond these clinical settings must be made with great caution. Also the samples are not demographically representative, and less so in the Virginian sample in study 1 where, for example, a large percentage of the parents had a high level of education.

A second and important limitation that should be mentioned is that mostly just one parent (the primary caretaker) presented to the clinics in Sweden and Virginia. Moreover, this parent was often the mother, and we cannot know how for sure how this might affect parent self-report and parent-report of child symptoms and improvement. The problem with absent fathers in clinical research studies seems to be global at present. This being said, there is some data to support that parents are in fair agreement over children's anxiety, depressive and externalizing problems (Engel et al., 1994; SeiffgeKrenke \& Kollmar, 1998).

A third limitation that warrants mention is the use of retrospective report. In the study on parenting and childhood anxiety, retrospective report was used in part to obtain parents' recollections of their own parents. The main criticism is concerned with the validity of such a technique. That is, how accurate are parents' memories of childhood experiences? Although care must be taken in drawing conclusions from retrospective reports, Robins and colleagues (1985) concluded from their study that memories of the childhood home were accurate enough to warrant use in case control studies and surveys. Also, further support for the use of retrieved and reconstructed recollections for increasing our understanding of intergenerational processes is provided by Grimes, Klein, and Putallaz (2004). Fourth, it is also important to address the sample size in this study, although large for a clinical study, in the context of analysis using factor analysis the sample size is small. One implication of this is that the power in the analysis might be 
too weak to discover small to moderate effects, which could also be important.

A fifth limitation is that in the clinical trial there was no check on child exposure following OST or, more importantly for the group receiving EST, at the post-assessment and follow-up. This means that we cannot be sure that treatment gains on the EST condition are solely due to just this intervention and not subsequent self-directed exposure. Also, in line with this, all groups were actually exposed to the phobic situation during the Behavioral Approach Test (BAT), although this was very brief. A control group was also exposed to this assessment at pre- and post-treatment with very small non-significant improvements. Another limitation is that although the BAT could be standardized for every specific phobia, it was difficult to create a "live" situation for some. Thus for some phobias, for example, thunderstorms, flying and rain, audiotapes, videotapes or visits to a museum with tropical forest and rain conditions were used as substitute for real life situations. For some of the BATs, then, ceiling effects were noted at pretreatment.

\subsection{Clinical implications}

There are several clinical implications that should be of direct use in the work with children and adolescents presenting with anxiety problems. First, the finding that motivation seems to be an important aspect in the assessment process on treatment entry not only suggests that children and adolescents should be screened for motivation, but also that there might be some benefit on time being spent on why they have come to the clinic, expectations they might have of a pending treatment and preparation of a pending treatment.

Second, clinicians are encouraged to use a multi-assessment approach, gathering information from both parents and children in the assessment process. This seems most reasonable as parent-child agreement seems to vary also, depending on if the child suffers from internalizing or externalizing problems.

Third, the OST appears to be an efficient and effective treatment for a variety of specific phobias in children and adolescents. As such, it is cost effective and the treatment seems to be portable outside of its country of origin. Furthermore, children and parents, at least from Sweden and Virginia, report overall that the treatment is beneficial. The OST has also been reported in previous studies to be both effective and experienced as something positive by children (Muris et al., 1998; Svensson, Larsson, \& Öst, 2002). This being said, it does seem that the one-session treatment should be delivered by extensively trained and experienced therapists for improved outcomes, even though the short treatment format might tempt us to view the treatment as simple and easy to implement. 
Fourth, there is now some accumulated knowledge that parental overprotection is associated with child anxiety, although the direction of this association is likely to be reciprocal. Also it seems that parents' own problems can be an asset if the psychopathology is not too serious. Overprotection and parental psychopathology should be incorporated when setting up treatment programs for children, and in the psychoeducation of parents on how best they can help their children overcome excessive anxiety and avoidance behavior.

\subsection{Suggestions for future research}

Future research on the treatment of specific phobias in youth might examine whether including parents and/or more formalized advice as how to work on maintenance gains after treatment might augment the treatment. However, including parents in the treatment sessions per se might not be more beneficial for the child (Kendall et al., 2008; Öst et al., 2001). For example, in the study by Öst and colleagues (2001), having a parent present in a OST did not enhance treatment effects, although it was not reported to be negative either. Interestingly, in a study of how children experience OST, for specific phobias, almost $21 \%$ of the 56 treated children reported that they would have appreciated more than one treatment session or the possibility of additional therapist contact for motivational purposes (Svensson, Larsson, \& Öst, 2002). This suggests a future design where one might extend the OST to a two session format, with a maximum of six hours of treatment (i.e., $3 \times 2$ hours), where specific and clear goals are to be reached before the child attempts the next step. This different approach to goal setting in combination with increased session time for practice might be more beneficial for children and adolescents, as they are likely to be at different developmental levels both within and across ages. This might also be beneficial for the therapists who are likely to have varying degrees of treatment experience. Other important issues to address in the future is parent-child agreement over a wider range of child anxiety disorders using the factors examined in the second study, in a cross-cultural comparison. Another interesting issue would be to test the four-factor parental model from the first study and analyze how this model would compare in larger clinical and non-clinical samples in Sweden as well as in other countries.

\subsection{Concluding remarks}

In the introduction to this dissertation it was noted that higher levels of anxiety have been reported across a period of 40 years, in both child and adult samples (Twenge, 2000). Although the meta-analysis by Twenge 
(2000) focused on American samples, it is not farfetched to suspect that similar anxiety development has taken place also in children and adults across the world, raising demands on prevention and treatment. Interestingly, in the above meta-analytic studies, anxiety was reported to correlate with low social connectedness, and maybe more importantly, with high environmental threat. This is important information to add to future preventive work, globally.

Some interesting findings came out of the present dissertation. Perhaps the most important is that children's phobias and fears can, for many children, be effectively treated with a one-session treatment. Also, that this treatment is portable to children and therapists in another country, where therapists may have a different educational background. It will be important to further analyze data from Sweden and Virginia to examine if the treatment also had an effect on the comorbid problems the children presented with. It would be extremely rewarding if, in the next birth cohort study, we can see a break in the increasing anxiety trend. 


\section{References}

Anderson, J. C., Williams, S., McGee, R., \& Silva, P. A. (1987). DSM-III disorders in preadolescent children. Archives of General Psychiatry, 44, 69-76.

American Psychiatric Association. (1987). Diagnostic and Statistical Manual of Mental Disorders, 3rd edn. Revised (DSM-III-R). Washington, DC: Author.

American Psychiatric Association. (1994). Diagnostic and Statistical Manual of Mental Disorders, 4th edn. (DSM-IV). Washington, DC: Author.

Baldwin, J. S., \& Dadds, M. R. (2007). Reliability and validity of parent and child versions of the Multidimensional Anxiety Scale for Children in community samples. Journal of American Academy of Child and Adolescent Psychiatry, 46, 252-260.

Bandura, A., Grusec, J. E., \& Menlove, F. L. (1967). Vicarious extinction of avoidance behavior. Journal of Personality and Social Psychology, 5, 16-23.

Bandura, A., \& Menlove, F. L. (1968). Factors determining vicarious extinction of avoidance behavior through symbolic modelling. Journal of Personality and Social Psychology, 8, 99-108.

Barlow, D. H. (2002). Anxiety and its disorders: The nature and treatment of anxiety and panic $\left(2^{\text {nd }}\right.$ edn). New York: Guilford Press.

Barrett, P. M., Rapee, R. M., Dadds, M. R. \& Ryan, S. M. (1996). Family enhancement of cognitive style in anxious and aggressive children: Threat bias and the FEAR effect. Journal of Abnormal Child Psychology, 24, 187-203.

Battjes, R. J., Gordon, M. S., O’Grady, K. E., Kinlock, T. W., \& Carswell, M. A. (2003). Factors that predict adolescent motivation for substance abuse treatment. Journal of Substance Abuse Treatment, 24, 221-232.

Beck, J. S., Beck, A. T., \& Jolly, J. B. (2001). Beck Youth Inventories of Emotional and Social Impairment Manual. San Antonio: Psychological Corporation.

Beidel, D. B. \& Turner, S. M. (2005). Childhood anxiety disorders: A guide to research and treatment. New York: Routledge.

Berg-Nielsen, T. S., Vika, A., \& Dahl, A. A. (2003). When adolescents disagree with their mothers: CBCL-YSR discrepancies related to maternal depression and adolescent self-esteem. Child: Care, Health and Development, 29, 207-213.

Biederman, J., Faraone, S. V., Marrs, A., Moore, P., Garcia, J., Ablon, S., Mick, E., Gershon, J., \& Kearns, M. E. (1997). Panic disorder and agoraphobia in consecutively referred children and adolescents. Journal of American Academy of Child and Adolescent Psychiatry, 36, 214-223.

Bird, H. R., Canino, G., Rubio-Stipec, M., Gould, M. S., Ribera, J., Sesman, M., Woodbury, M., Huertas-Goldman, S., Pagan, A., Sanchez-Lacay, A., \& Moscoso, M. (1988). Estimates of the prevalence of childhood maladjustment in a community survey in Puerto Rico. Archives of General Psychiatry, 45, 1120 1126.

Bornstein, M. H. (2002). Handbook of parenting: Volume 1. Children and parenting $\left(2^{\text {nd }}\right.$ edn). New Jersey: Lawrence Erlbaum Associates. 
Brown, T. A., Di Nardo, P. A., \& Barlow, D. H. (1994). Anxiety Disorders Interview Schedule for DSM-IV. Albany, NY: Graywind Publications Inc.

Bögels, S. M. \& Brechman-Toussaint, M. (2006). Family issues in child anxiety: Attachment, family functioning, parental rearing and beliefs. Clinical Psychology Review, 26, 834-856.

Cantwell, D. P. \& Baker, L. (1989). Stability and natural history of DSM-III childhood diagnoses. Journal of the American Academy of Child and Adolescent Psychiatry, 28, 691-700.

Chambers, J. A., Power, K. G., \& Durham, R. C. (2004). Parental styles and longterm outcome following treatment for anxiety disorders. Clinical Psychology \& Psychotherapy, 11, 187-198.

Chambers, J. A., Power, K. G., Loucks, N., \& Swanson, V. (2000). Psychometric properties of the Parental Bonding Instrument and its association with psychological distress in a group of incarcerated young offenders in Scotland. Social Psychiatry and Psychiatric Epidemiology, 35, 318-325.

Chorpita, B. F., Brown, T. A., \& Barlow, D. H. (1998). Perceived control as a mediator of family environment in etiological models of childhood anxiety. Behavior Therapy, 29, 457-476.

Choudhury, M. S., Pimentel, S. S., \& Kendall, P. C. (2003). Childhood anxiety disorders: Parent-child (dis)agreement using a structured interview for the DSM-IV. Journal of the American Academy of Child and Adolescent Psychiatry, 42, 957-964.

Comer, J. S., \& Kendall, P. C. (2004). A symptom-level examination of parent-child agreement in the diagnosis of anxious youths. Journal of the American Academy of Child and Adolescent Psychiatry, 43, 878-886.

Cornwall, E., Spence, S. H., \& Schotte, D. (1996). The effectiveness of emotive imagery in the treatment of darkness phobia in children. Behaviour Change, 13, 223-229.

Costello, E. J., Angold, A., \& Keeler, G. P. (1999). Adolescent outcomes of childhood disorders: The consequences of severity and impatient. Journal of the American Academy of Child and Adolescent Psychiatry, 38, 121-128.

Costello, E. J., Costello, A. J., Edelbrock, C., Burns, B. J., Dulcan, M. K., Brent, D., \& Janiszewski, S. (1988). Psychiatric disorders in pediatric primary care. Archives of General Psychiatry, 45, 1107-1116.

Cox, B. J., Enns, M. W., \& Clara, I. P. (2000). The Parental Bonding Instrument: Confirmatory evidence for a three-factor model in a psychiatric clinical sample and in the National Comorbidity Survey. Social Psychiatry and Psychiatric Epidemiology, 35, 353-357.

Darling, N., Hames, K., \& Cumsille, P. (2000). When parents and adolescents disagree: Disclosure strategies and motivations. Poster presented at the Society for Research in Adolescence Development, Biannual meeting, Chicago, IL. Retrieved April 17, 2007, from http://www.oberlin.edu/faculty/ndarling/lab/.

Davis, T. E. \& Ollendick, T. H. (2005). Empirically supported treatments for specific phobia in children: Do efficacious treatments address the components of a phobic response? Clinical Psychology-Science and Practice, 12, 144-160.

Dewis, L. M., Kirkby, K. C., Martin, F., Daniels, B. A., Gilroy, L. J., \& Menzies, R. G. (2001). Computer-aided vicarious exposure versus live graded exposure for spider phobia in children. Journal of Behaviour Therapy, 32, 17-27.

De Los Reyes, A. \& Kazdin, A. E. (2005). Informant discrepancies in the assessment of childhood psychopathology: A critical review, theoretical framework, and recommendations for further study. Psychological Bulletin, 131, 483-509. 
DiBartolo, P. M., Albano, A. M., Barlow, D. H., \& Heimberg, R. G. (1998). Crossinformant agreement in the assessment of social phobia in youth. Journal of Abnormal Child Psychology, 26, 213-220.

Dong, Q., Yang, B., \& Ollendick, T. H. (1994). Fears in Chinese children and adolescents and their relations to anxiety and depression. Journal of Child Psychology and Psychiatry and Allied Disciplines, 35, 351-363.

Edelbrock, C., Costello, A. J., Dulcan, M. K., Conover, N. C., \& Kala, R. (1986). Parent-child agreement on child psychiatric symptoms assessed via structured interview. Journal of Child Psychology and Psychiatry, 27, 181-190.

Ek, L., \& Israelsson, P. (2008). En psykometrisk utprovning och normering av Child Inhibition Scale. Psykologexamensuppsats vid Institutionen för Psykologi, Stockholm: Stockholms universitet.

Elbedour, S., Shulman, S., \& Kedem, P. (1997). Children's fears: Cultural and developmental perspectives. Behaviour Research and Therapy, 35, 491-496.

Elliott, G. C. (1982). Self-esteem and self-presentation among the young as a function of age and gender. Journal of Youth and Adolescence, 11, 135-153.

Engel, N. A., Rodrigue, J. R., \& Geffken, G. R. (1994). Parent-child agreement on ratings of anxiety in children. Psychological reports, 75, 1251-1260.

Essau, C. A., Conradt, J., \& Petermann, F. (2000). Frequency, comorbidity, and psychosocial impairment of specific phobia in adolescents. Journal of Clinical Child Psychology, 29, 221-231.

Forget-Dubois, N., Boivin, M., Dionne, G., Pierce, T., Tremblay, M. E. \& Perussé, D. (2007). A longitudinal twin study of the genetic and environmental etiology of maternal hostile-reactive behavior during infancy and toddlerhood. Infant Behavior and Development, 30, 453-465.

Garber, J., Van Slyke, D. A., \& Walker, L. S. (1998). Concordance between mothers' and children's reports of somatic and emotional symptoms in patients with recurrent abdominal pain or emotional disorders. Journal of Abnormal Child Psychology, 26, 381-391.

Gerlsma, C., Emmelkamp, P. M. G., \& Arrindell, W. A. (1990). Anxiety, depression, and perception of early parenting: A meta-analysis. Clinical Psychology Review, 10, 251-277.

Ghaderi, A., Mårtensson, M., \& Schwan, H. (2005). "Everybody’s different”: A primary prevention program among fifth grade school children. Eating Disorders, 13, 245-259.

Graziano, A. M., DeGiovanni, I. S., \& Garcia, K. A. (1979). Behavioral treatment of children's fears: A review. Psychological Bulletin, 86, 804-830.

Graziano, A. M., \& Mooney, K. C. (1980). Family self-control instruction for children's nighttime fear reduction. Journal of Consulting and Clinical Psychology, 48, 206-213.

Graziano, A. M., \& Mooney, K. C. (1982). Behavioral treatment of "night fears" in children: Maintenance of improvement at 21/2- to 3-year follow-up. Journal of Consulting and Clinical Psychology, 50, 598-599.

Grills, A. E., \& Ollendick, T. H. (2002). Issues in parent-child agreement: The case of structured diagnostic interviews. Clinical Child and Family Psychology Review, 5, 57-83.

Grills, A. E., \& Ollendick, T. H. (2003). Multiple informant agreement and the Anxiety Disorders Interview Schedule for parents and children. Journal of the American Academy of Child and Adolescent Psychiatry, 42, 30-40.

Grimes, C. L., Klein, T. P., \& Putallaz, M. (2004). Parents' relationships with their parents and peers: Influences on children's social development. DC, US: 
American Psychological Association, [URL:http://www.apa.org/books]: Washington.

Hall, G. S. (1897). A study of fears. The American Journal of Psychology, 8, 147157.

Hampe, E., Noble, H., Miller, L. C. \& Barrett, C. L. (1973). Phobic children one and two years posttreatment. Journal of Abnormal Psychology, 82, 446-453.

Harlaar, N., Santtila, P., Björklund, J., Alanko, K., Jern, P., Varjonen, M., von der Pahlen, B. \& Sandnabba, K. (2008). Retrospective reports of parental physical affection and parenting style: A study of finnish twins. Journal of Family Psychology, 22, 605-613.

Hudson, J. L., \& Rapee, R. M. (2001). Parent-child interactions and anxiety disorders: An observational study. Behaviour Research and Therapy, 39, 14111427.

In-Albon, T., \& Schneider, S. (2007). Psychotherapy of childhood anxiety disorders: A meta-analysis. Psychotherapy and Psychosomatics, 76, 15-24.

Jensen, P. S., Rubio-Stipec, M., Canino, G., Bird, H. R., Dulcan, M. K., SchwabStone, M. E., \& Lahey, B.B. (1999). Parent and child contributions to diagnosis of mental disorder: Are both informants always necessary? Journal of the American Academy of Child and Adolescent Psychiatry, 38, 1569-1579.

Johnson, S. B., \& Melamed, B. G. (1979). The assessment and treatment of children's fears. In B. B. Lahey \& A. E. Kazdin (Eds.). Advances in Clinical Child Psychology, (vol. 2; pp. 107-139). New York: Plenum Press.

Jones, M. C. (1924). The elimination of children's fears. Journal of Experimental Psychology, 7, 382-390.

Jöreskog, K. \& Sörbom, D. (1996). LISREL 8: User's reference guide. Chicago IL: Scientific Software International, Inc.

Kagan, J., Reznick, J. S., Clarke, C., Snidman, N., \& Garcia-Coll, C. (1984). Behavioral inhibition to the unfamiliar. Child Development, 55, 2212-2225.

Kagan, J., Reznick, J. S., \& Snidman, N. (1988). Biological bases of childhood shyness. Science, 240, 167-171.

Kagan, J. \& Snidman, N. (1991). Temperamental factors in human development. American Psychologist, 46, 865-862.

Kanfer, F. H., Karoly, P., \& Newman, A. (1975). Reduction of children's fear of the dark by competence-related and situational threat-related verbal cues. Journal of Consulting and Clinical Psychology, 43, 251-258.

Keijsers, G. P. J., Schaap, C. P., Hoogduin, C. A. L., Hoogsteyns, B., \& de Kemp, E. C. M. (1999). Preliminary results of a new instrument to assess patient motivation for treatment in cognitive-behaviour therapy. Behavioural and Cognitive Psychotherapy, 27, 165-179.

Kendall, P. C. (1993). Cognitive-behavioral therapies with youth-guiding theory, current status, and emerging developments. Journal of Consulting Clinical Psychology, 61, 235-247.

Kendall, P. C., Brady, E. U., \& Verduin, T. L. (2001). Comorbidity in childhood anxiety disorders and treatment outcome. Journal of the American Academy of Child and Adolescent Psychiatry, 40, 787-794.

Kendall, P. C., Hudson, J. L., Gosch, E., Flannery-Schroeder, E., \& Suveg, C. (2008). Cognitive-Behavioral Therapy for anxiety disordered youth: A randomized clinical trial evaluating child and family modalities. Journal of Consulting and Clinical Psychology, 76, 282-297.

Kendler, K. S. (1996). Parenting: A genetic-epidemiologic perspective. American Journal of Psychiatry, 153, 11-20. 
Kendler, K. S., Gardner, C. O., Annas, P., Neale, M. C., Eaves, L. J., \& Lichtenstein, P. (2008). A longitudinal twin study of fears from middle childhood to early adulthood. Evidence for a developmentally dynamic genome. Archives of General Psychiatry, 65, 421-429.

Kessler, R. C., Berglund, P., Demler, O., Jin, R., Merikangas, K. R., \& Walters, E. E. (2005). Lifetime prevalence and age-of-onset distributions of DSM-IV disorders in the national comorbidity survey replication. Archives of General Psychiatry, 62, 593-602.

King, N. J., Heyne, D., Gullone, E., \& Molloy, G. N. (2001). Usefulness of emotive imagery in the treatment of childhood phobias: clinical guidelines, case examples and issues. Counselling Psychology Quartely, 14, 95-101.

King, N. J., Muris, P., Ollendick, T. H., \& Gullone, E. (2005). Childhood fears and phobias: Advances in assessment and treatment. Behaviour Change, 22, 199 211.

King, N. J., Ollendick, T. H., \& Murphy, (1997). Assessment of childhood phobias. Clinical Psychology, Review, 17, 667-687.

Knafo, A., \& Plomin, R. (2006). Parental discipline and affection and children's prosocial behavior: Genetic and environmental links. Journal of Personality and Social Psychology, 90, 147-164.

Krain, A. L., \& Kendall, P. C. (2000). The role of parental emotional distress in parent report of child anxiety. Journal of Clinical Child Psychology, 29, 328335.

Last, C. G., Perrin, S., Hersen, M., \& Kazdin, A. E. (1992). DSM-III-R Anxiety disorders in children: Sociodemographic and clinical characteristics. Journal of the American Academy of Child and Adolescent Psychiatry, 31, 1070-1076.

Last, C. G., Perrin, S., Hersen, M., \& Kazdin, A. E. (1996). A prospective study of childhood disorders. . Journal of American Academy of Child and Adolescent Psychiatry, 35, 1502-1510.

Lazarus, A. A., \& Abramowitz. (1962). The use of "emotive imagery" in the treatment of children's phobias. Journal of Mental Science, 108, 191-195.

Lichtenstein, P., \& Annas, P. (2000). Heritability and prevalence of specific fears and phobias in childhood. Journal of Child Psychology and Psychiatry, 41, 927937.

Lieb, R., Wittchen, H., Hofler, M., Fuetsch, M., Stein, M., \& Merikangas, K. (2000). Parental psychopathology, parenting styles, and the risk of social phobia in offspring: A prospective-longitudinal community study. Archives of General Psychiatry, 57, 859-866.

Maccoby, E. E. (2000). Parenting and its effects on children: On reading and misreading behavior genetics. Annual Review Psychology, 51, 1-27.

March, J. S., Parker, J. D. A., Sullivan, K., Stallings, P., \& Conners, C. K. (1997). The Multidimensional Anxiety Scale for Children (MASC): Factor structure, reliability, and validity. Journal of American Academy of Child and Adolescent Psychiatry, 36, 554-565.

Marks, I. M. (1969). Fears and Phobias. New York: Academic Press.

Marks, I. M. (1987). The development of normal fear: A review. Journal of Child Psychology and Psychiatry, 28, 667-697.

Martin, J. L., Ford, C. B., Dyer-Freidman, J., Tang, J., \& Huffman, L. C. (2004). Patterns of agreement between parent and child ratings of emotional and behavioral problems in an outpatient clinical setting: When children endorse more problems. Journal of Developmental and Behavioral Pediatrics, 25, 150 155. 
McGee, R., Feehan, M., Williams, S., Partridge, F., Silva, P. A., \& Kelly, J. (1990). DSM-III disorders in a large sample of adolescents. Journal of American Academy of Child and Adolescent Psychiatry, 29, 611-619.

Menzies, R. G., \& Clarke, J. C. (1993). A comparison of in vivo and vicarious exposure in the treatment of childhood water phobia. Behaviour Research and Therapy, 31, 9-15.

Menzies, R. G. \& Clarke, J. C. (1995). The etiology of phobias: A nonassociative account. Clinical Psychology Review, 15, 23-48.

Miller, L. C., Barrett, C. L., Hampe, E., \& Noble, H. (1972). Comparison of reciprocal inhibition, psychotherapy, and waiting list control for phobic children. Journal of Abnormal Psychology, 79, 269-279.

Moore, P. S., Whaley, S. E., \& Sigman, M. (2004). Interactions between mothers and children: Impacts of maternal and child anxiety. Journal of Abnormal Psychology, 113, 471-476.

Mowrer, O. H. (1939). A stimulus-response analysis of anxiety and its role as a reinforcing agent. Psychological Review, 46, 553-565.

Mowrer, O. H. (1956). Two-factor learning theory reconsidered, with special reference to secondary reinforcement and the concept of habit. Psychological Review, 63, 114-128.

Munroe, R. L., \& Munroe, R. H. (1977). Cooperation and competition among east African and American children. The Journal of Social Psychology, 101, 145146.

Muris, P., Merckelbach, H., de Jong, P. J., \& Ollendick, T. H. (2002). The etiology of specific fears and phobias in children: A critique of the non-associative account. Behaviour Research and Therapy, 40, 185-195.

Muris, P., Merckelbach, H., Holdrinet, I., \& Sijsenaar, M. (1998). Treating phobic children: Effects of EMDR versus exposure. Journal of Consulting and Clinical Psychology, 66, 193-198.

Muris, P., Merckelbach, H., Van Haaften, H., \& Mayer, B. (1997). Eye movement desensitisation and reprocessing versus exposure in vivo. British Journal of Psychiatry, 171, 82-86.

Muris, P., Steerneman, P., Merckelbach, H. \& Meesters, C. (1996). The role of parental fearfulness and modeling in children's fear. Behaviour Research and Therapy, 34, 265-268.

Obler, M., \& Terwilliger, R. F. (1970). Pilot study on the effectiveness of systematic desensitization with neurologically impaired children with phobic disorders. Journal of Consulting and Clinical Psychology, 34, 314-318.

Oh, K. J., Shin, Y. J., Moon, K. J., Hudson, J. L., \& Rapee, R. M. (2002). Childrearing practices and psychological disorders in children: Cross-cultural comparison of Korea and Australia. Yonsei Medical Journal, 43, 411-419.

Ollendick, T. H. (1983). Reliability and validity of the Revised Fear Survey Schedule for Children (FSSC-R). Behaviour Research and Therapy, 21, 685692.

Ollendick, T. H., Hagopian, L. P., \& King, N. J. (1997). Specific phobias in children. In G. C. L. Davey (Ed.), Phobias. A handbook of theory, research and treatment. Chichester, England: Wiley.

Ollendick, T.H., \& Horsch, L.M. (2007). Fears in children and adolescents: Relations with child anxiety sensitivity, maternal overprotection, and maternal phobic anxiety. Behavior Therapy, 38, 402-411.

Ollendick, T. H., \& King, J. N. (1994). Fears and their level of interference in adolescents. Behaviour Research and Therapy, 32, 635-638. 
Ollendick, T. H., \& King, N. J. (1998). Empirically supported treatments for children with phobic and anxiety disorders: Current status. Journal of Clinical Child Psychology, 27, 156-167.

Ollendick, T. H., Yang, B., King, N. J., Dong, Q., \& Akande, A. (1996). Fears in American, Australian, Chinese, and Nigerian children and adolescents: A crosscultural study. Journal of Child Psychology and Psychiatry, 37, 213-220.

Poulton, R., \& Menzies, R. G. (2002). Non-associative fear acquisition: A review of the evidence from retrospective and longitudinal research. Behaviour Research and Therapy, 40, 127-149.

Parker, G., Tupling, H., \& Brown, L. B. (1979). A Parental Bonding Instrument. British Journal of Medical Psychology, 52, 1-10.

Rachman, S. (1977). The conditioning theory of fear acquisition: a critical examination. Behaviour Research \& Therapy, 15, 375-387.

Rapee, R. M. (1997). Potential role of childrearing practices in the development of anxiety and depression. Clinical Psychology Review, 17, 47-67.

Rapee, R. M., Barrett, P. M., Dadds, M. R., \& Evans, L. (1994). Reliability of the DSM-III-R childhood anxiety disorders using structured interview: Interrater and parent-child agreement. Journal of the American Academy of Child and Adolescent Psychiatry, 33, 984-992.

Regier, D. A., Narrow, W. E., \& Rae, D. S. (1993). The epidemiology of anxiety disorders: The Epidemiologic Catchment Area (ECA) experience. Journal of Psychiatric Research, 24, 3-14.

Reich, W., Herjanic, B., Welner, Z., \& Gandhy, P. R. (1982). Development of a structured psychiatric interview for children: Agreement on diagnosis comparing child and parent interviews. Journal of Abnormal Child Psychology, $10,325-336$.

Renouf, A. G., \& Kovacs, M. (1994). Concordance between mothers' reports and children's self-reports of depressive symptoms: A longitudinal study. Journal of the American Academy of Child and Adolescent Psychiatry, 33, 208-216.

Robins, L. N., Schoenberg, S. P., Holmes, S. J., Ratcliff, K. S., Benham, A., \& Works, J. (1985). Early home environment and retrospective recall: A test of concordance between siblings with and without psychiatric disorders. American Journal of Orthopsychiatry, 55, 27-39.

Rose, R. J., \& Ditto, W. B. (1983). A developmental-genetic analysis of common fears from early adolescence to early adulthood. Child Development, 54, 361368.

Safford, S. M., Kendall, P. C., Flannery-Schroeder, E., Webb, A., \& Sommer, H. (2005). A longitudinal look at parent-child diagnostic agreement in youth treated for anxiety disorders. Journal of Clinical Child and Adolescent Psychology, 34, 747-757.

Seiffge-Krenke, I., \& Kollmar, F. (1998). Discrepancies between mothers' and fathers' perceptions of sons' and daughters' problem behaviour: A longitudinal analysis of parent-adolescent agreement on internalising and externalising problem behaviour. Journal of Child Psychology and Psychiatry, and Allied Disciplines, 39, 687-697.

Shamir-Essakow, G., Ungerer, J. A., \& Rapee, R. M. (2005). Attachment, behavioral inhibition, and anxiety in preschool children. Journal of Abnormal Child Psychology, 33, 131-143.

Shams, M., \& Williams, R. (1995). Differences in perceived parental care and protection and related psychological distress between British Asian and nonAsian adolescents. Journal of Adolescence, 18, 329-348. 
Sheslow, D. V., Bondy, A. S., \& Nelson, R. O. (1983). A comparison of graduated exposure, verbal coping skills, and their combination in the treatment of children's fear of the dark. Child \& Family Behavior Therapy, 4, 33-45.

Shortt, A. L., Barrett, P. M., Dadds, M. R., \& Fox, T. L. (2001). The influence of family and experimental context on cognition in anxious children. Journal of Abnormal Child Psychology, 29, 585-596.

Silverman, W. K., \& Albano, A. M. (1996). The Anxiety Disorders Interview Schedule for DSM-IV: Child and Parent Versions. San Antonio TX: Psychological Corporation.

Silverman, W. K., \& Eisen, A. R. (1992). Age differences in the reliability of parent and child reports of child anxious symptomatology using a structured interview. Journal of the American Academy of Child and Adolescent Psychiatry, 31, $117-$ 124.

Silverman, W. K., Kurtines, W. M., Ginsburg, G. S., Weems, C. F., Rabian, B., \& Serafini, L. T. (1999). Contingency management, self-control, and education support in the treatment of childhood phobic disorders: A randomized clinical trial. Journal of Consulting and Clinical Psychology, 67, 675-687.

Silverman, W. K., \& Moreno, J. (2005). Specific phobia. Child and Adolescent Psychiatric Clinics of North America, 14, 819-843.

Silverman, W. K., Saavedra, L. M., \& Pina, A. A. (2001). Test-retest reliability of anxiety symptoms and diagnoses with the Anxiety Disorders Interview Schedule for DSM-IV: Child and Parent Versions. Journal of the American Academy of Child and Adolescent Psychiatry, 40, 937-944.

Siqueland, L., Kendall, P. C., \& Steinberg, L. (1996). Anxiety in children: Perceived family environments and observed family interaction. Journal of Clinical Child Psychology, 25, 225-237.

Stein, D. M., \& Lambert, M. J. (1995). Graduate training in psychotherapy: Are therapy outcomes enhanced? Journal of Consulting and Clinical Psychology, 63, 182-196.

Steinhausen, H.-C., Metzke, CW., Meier, M., \& Kannenberg, R. (1998). Prevalence of child and adolescent psychiatric disorders: The Zürich epidemiological study. Acta Psychiatrica Scandinavica, 98, 262-271.

Svensson, L., Larsson, Å., \& Öst, L.-G. (2002). How children experience briefexposure treatment of specific phobias. Journal of Clinical Child and Adolescent Psychology, 31, 80-89.

Svensson, L., \& Öst, L.-G. (1999). Fears in Swedish children: A normative study of the Fear Survey Schedule for Children-Revised. Scandinavian Journal of Behavior Therapy, 28, 23-36.

Twenge, J. M. (2000). The age of anxiety? Birth cohort change in anxiety and neuroticism, 1952-1993. Journal of Personality and Social Psychology, 79, 1007-1021.

Uji, M., Tanaka, N., Shono, M., \& Kitamura, T. (2006). Factorial structure of the Parental Bonding Instrument (PBI) in Japan: A study of cultural, developmental, and gender influences. Child Psychiatry and Human Development, 37, 115-132.

Ultee, C. A., Griffioen, D., \& Schellekens, J. (1982). The reduction of anxiety in children: A comparison of the effects of 'systematic desensitization in vitro' and 'systematic desensitization in vivo'. Behaviour Research and Therapy, 20, 6167.

Vasey, M. W., \& Dadds, M. R. (2002). An introduction to the developmental psychopathology of anxiety. In M. W. Vasey \& M. R. Dadds (Eds.), The developmental psychopathology of anxiety. Oxford: Oxford University Press. 
Verhulst, F. C., van der Ende, J., Ferdinand, R. F., \& Kasius, M. C. (1997). The prevalence of DSM-III-R diagnoses in a national sample of Dutch adolescents. Archives of General Psychiatry, 54, 329-336.

Weems, C. F., Silverman, W. K., Saavedra, L. M., Pina, A. A. \& White-Lumpkin, P. (1999). The discrimination of children's phobias using the revised Fear Survey Schedule for Children. Journal of Child Psychology and Psychiatry, 40, 941952.

Weisz, J. R., Sigman, M., Weiss, B., \& Mosk, J. (1993). Parent reports of behavioral and emotional problems among children in Kenya, Thailand and the United States. Child Development, 64, 98-109.

Wittchen, H.-U., Nelson, C. B., \& Lachner, G. (1998). Prevalence of mental disorders and psychosocial impairments in adolescents and young adults. Psychological Medicine, 28, 109-126.

Wolitzky-Taylor, K. B., Horowitz, J. D., Powers, M. B., \& Telch, M. J. (2008). Psychological approaches in the treatment of specific phobias: A meta-analysis. Clinical Psychology Review, 28, 1021-1037.

Wolpe, J. (1958). Psychotherapy by reciprocal inhibition. Stanford, CA: Stanford University Press.

Wood, J. J., McLeod, B. D., Sigman, M., Hwang, W.-C., \& Chu, B. C. (2003). Parenting and childhood anxiety: Theory, empirical findings, and future directions. Journal of Child Psychology and Psychiatry, 44, 134-151.

Yeh, M., \& Weisz, J. R. (2001). Why are we here at the clinic? Parent-child (dis)agreement on referral problems at outpatient treatment entry. Journal of Consulting and Clinical Psychology, 69, 1018-1025.

Zlomke, K. \& Davis III, T. E. (2008). One-session treatment of specific phobias: A detailed description and review of treatment efficacy. Behavior Therapy, 39, 207-223.

Öhman, A. \& Mineka, S. (2001). Fears, phobias and preparedness: Toward an evolved module of fear and fear learning. Psychological Review, 108, 483-522.

Öst, L.-G. (1987). Age of onset in different phobias. Journal of Abnormal Psychology, 96, 223-229.

Öst, L.-G. (1989). One-session treatment for specific phobias. Behaviour Research and Therapy, 27, 1-7.

Öst, L.-G. (1997). Rapid treatment of specific phobias. In G. C. L. Davey (Ed.), Phobias: A handbook of theory, research and treatment. Chichester, England: Wiley.

Öst, L.-G., Svensson, L., Hellström, K., \& Lindwall, R. (2001). One-session treatment of specific phobias in youths: A randomized clinical trial. Journal of

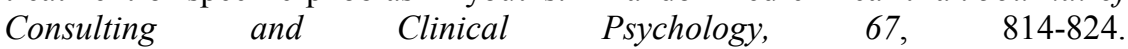


